\title{
Improved Bioavailability of Ebastine through Development of Transfersomal Oral Films
}

\author{
Nayyer Islam ${ }^{1} \mathbb{D}$, Muhammad Irfan ${ }^{1, *}$, Ameer Fawad Zahoor ${ }^{2} \mathbb{D}$, Muhammad Shahid Iqbal ${ }^{3} \mathbb{D}$, \\ Haroon Khalid Syed ${ }^{1}{ }^{\mathbb{D}}$, Ikram Ullah Khan ${ }^{1}{ }^{\mathbb{D}}$, Akhtar Rasul ${ }^{1}{ }^{\mathbb{D}}$, Salah-Ud-Din Khan ${ }^{4}$, Alaa M. Alqahtani ${ }^{5} \mathbb{D}$, \\ Muzzamil Ikram ${ }^{6}$, Muhammad Abdul Qayyum ${ }^{7}$, Ahmed Khames ${ }^{8}$, Sana Inam ${ }^{1}$ \\ and Mohammed A. S. Abourehab 9,10
}

1 Department of Pharmaceutics, Faculty of Pharmaceutical Sciences, Government College University, Faisalabad 38000, Pakistan; nayyerislam1@gmail.com (N.I.); haroonkhalid80@gmail.com (H.K.S.); ikramglt@gmail.com (I.U.K.); akhtar.rasul@gcuf.edu.pk (A.R.); drsanainam@gmail.com (S.I.)

2 Department of Chemistry, Government College University, Faisalabad 38000, Pakistan; fawad.zahoor@googlemail.com

3 Department of Clinical Pharmacy, College of Pharmacy, Prince Sattam bin Abdulaziz University, Alkharj 11942, Saudi Arabia; m.javed@psau.edu.sa

4 Department of Biochemistry, College of Medicine, Imam Mohammad Ibn Saud Islamic University (IM-SIU), Riyadh 11432, Saudi Arabia; sdikhan@imamu.edu.sa

5 Pharmaceutical Chemistry Department, College of Pharmacy, Umm Al-Qura University, Makkah 21955, Saudi Arabia; amqahtani@uqu.edu.sa

6 Department of Radiology, Madinah Teaching Hospital, The University of Faisalabad, Faisalabad 38000, Pakistan; drmuzzamilirfan89@gmail.com

check for updates

Citation: Islam, N.; Irfan, M.; Zahoor, A.F.; Iqbal, M.S.; Syed, H.K.; Khan, I.U.; Rasul, A.; Khan, S.-U.-D.; Alqahtani, A.M.; Ikram, M.; et al. Improved Bioavailability of Ebastine through Development of Transfersomal Oral Films. Pharmaceutics 2021, 13, 1315. https://doi.org/10.3390/ pharmaceutics 13081315

Academic Editor: Fiona McCartney

Received: 17 June 2021

Accepted: 7 August 2021

Published: 23 August 2021

Publisher's Note: MDPI stays neutral with regard to jurisdictional claims in published maps and institutional affiliations.

Copyright: (C) 2021 by the authors Licensee MDPI, Basel, Switzerland. This article is an open access article distributed under the terms and conditions of the Creative Commons Attribution (CC BY) license (https:/ / creativecommons.org/licenses/by/ $4.0 /)$.
7 Department of Chemistry, Division of Science \& Technology, University of Education, Lahore 5600, Pakistan; hmaqayyum@ue.edu.pk

8 Department of Pharmaceutics and Industrial Pharmacy, Beni-Suef University, Beni-Suef 62514, Egypt; Ahmed.khamies@pharm.bsu.edu.eg

9 Department of Pharmaceutics and Industrial Pharmacy, Faculty of Pharmacy, Minia University, Minia 61519, Egypt; maabourehab@uqu.edu.sa

10 Department of Pharmaceutics, Faculty of Pharmacy, Umm Al-Qura University, Makkah 21955, Saudi Arabia

* Correspondence: manipharma@yahoo.co.uk or drmirfan@gcuf.edu.pk; Tel.: +92-3349392369

Abstract: The main objective of this research work was the development and evaluation of transfersomes integrated oral films for the bioavailability enhancement of Ebastine (EBT) to treat allergic rhinitis. The flexible transfersomes, consisting of drug (EBT), lipid (Phosphatidylcholine) and edge activator (EA) Polyoxyethylene sorbitan monooleate or Sorbitan monolaurate, were prepared with the conventional thin film hydration method. The developed transfersomes were further integrated into oral films using the solvent casting method. Transfersomes were evaluated for their size distribution, surface charge, entrapment efficiency (EE\%) and relative deformability, whereas the formulated oral films were characterized for weight, thickness, $\mathrm{pH}$, folding endurance, tensile strength, $\%$ of elongation, degree of crystallinity, water content, content uniformity, in vitro drug release and ex vivo permeation, as well as in vivo pharmacokinetic and pharmacodynamics profile. The mean hydrodynamic diameter of transfersomes was detected to be $75.87 \pm 0.55 \mathrm{~nm}$ with an average PDI and zeta potential of $0.089 \pm 0.01$ and $33.5 \pm 0.39 \mathrm{mV}$, respectively. The highest deformability of transfersomes of $18.52 \mathrm{mg} / \mathrm{s}$ was observed in the VS-3 formulation. The average entrapment efficiency of the transfersomes was about $95.15 \pm 1.4 \%$. Transfersomal oral films were found smooth with an average weight, thickness and tensile strength of $174.72 \pm 2.3 \mathrm{mg}, 0.313 \pm 0.03 \mathrm{~mm}$ and $36.4 \pm 1.1 \mathrm{MPa}$, respectively. The folding endurance, $\mathrm{pH}$ and elongation were found $132 \pm 1,6.8 \pm 0.2$ and $10.03 \pm 0.4 \%$, respectively. The ex vivo permeability of EBT from formulation ETF-5 was found to be approximately 2.86 folds higher than the pure drug and 1.81 folds higher than plain film (i.e., without loaded transfersomes). The relative oral bioavailability of ETF-5 was 2.95- and 1.7-fold higher than that of EBT-suspension and plain film, respectively. In addition, ETF-5 suppressed the wheal and flare completely within $24 \mathrm{~h}$. Based on the physicochemical considerations, as well as in vitro and in vivo characterizations, it is concluded that the highly flexible transfersomal oral films (TOFs) effectively improved the bioavailability and antihistamine activity of EBT. 
Keywords: bioavailability; ebastine; edge activator; in vivo; phospholipids; transfersomes

\section{Introduction}

Ebastine (EBT), is a histamine $\mathrm{H}_{1}$ receptor blocker which is used to treat different allergic diseases [1]. The prevalence of allergic diseases is more than $20 \%$ of the global population [2]. It is estimated that $28.5 \%$ of European population is affected by allergic rhinitis every year [3]. The effectiveness of antihistaminic products varies considerably from one another [4]. To cope with allergic diseases, it is necessary to improve the efficiency of available treatment options. As far as EBT (BCS-II drug) is concerned, its oral bioavailability is about $40 \%[5,6]$. To obtain maximum therapeutic benefits from EBT, its oral bioavailability should be enhanced [7]. For that purpose, several approaches have been employed by scientists to increase the bioavailability of EBT, such as complexation, nanoparticle formulation, fast disintegrating tablets and microemulsion, as well as spray drying technique [8-11]. Importantly, researchers are also exploring different ways to enhance absorptions of drug molecules to increase oral bioavailability. The low permeation of drugs is generally caused by mucosal barriers. The rationale of choosing transfersomes-based films was to cross these mucosal barriers. Thus, the enhanced and extended absorption of EBT from the oral films might increase the bioavailability. Therefore, transmucosal delivery of EBT through GIT could possibly be enhanced by encapsulating it into transfersomes [12].

Transfersomes are ultra-deformable carriers composed mainly of phospholipids and edge activators (EAs). The phospholipids amphiphilic molecules comprise a hydrophilic head and hydrophobic tail groups in their structure [13]. Besides, the EA preserves the integrity of transfersomes when going across small channels, as a result, maximizing stability thus deformity is procured [14]. It has been reported that nonionic surfactants, such as polyoxyethylene sorbitan monooleate (Tween $80^{\circledR}$ ) and sorbitan monolaurate (Span $20^{\circledR}$ ), are efficient edge activators (EAs) for phosphatidylcholine (PC) [15]. Transfersomes have been found suitable for the delivery of hydrophilic as well as hydrophobic therapeutic candidates through the intact membranes, thus increasing therapeutic delivery, owing to their flexible structure [16]. The highly deformable property of transfersomes allows them to penetrate through tight junctions and small pores present in membranes [17]. Similarly, phospholipids and EAs collectively confer the squeezing properties to the transfersomes [18].

Nevertheless, transfersomes in aqueous dispersion may create problems in the handling and storage of incorporated drugs. Fusion, leakage, hydrolysis and aggregation may limit the benefits of transfersomes as carriers [19]. However, stability can be provided to transfersomes by converting them into solid state. The characteristics of transfersomes could be possibly improved by integrating them into oral films. In addition, the oral absorption of low bioavailable drugs is reported to be increased by the administration of oral films [20-22]. Film-forming polymers, in the presence of other additives (e.g., plasticizers, penetration enhancer, flavors and sweeteners), play a critical role in the development of effective oral films. Previously, hydroxypropyl methylcellulose (HPMC-K15M) was investigated for the development of oral films [23,24]. The main reason for selecting HPMC is that it provides appropriate mechanical strength to the films [25-27]. The significance of current research work is that transfersomes-loaded oral films offer more absorptive properties than existing EBT formulations. Besides, transfersomes have the ability to diffuse through lipid membranes by modulating the membrane bilayer structure, acting as a permeation enhancer and making pathway to improve the absorption of drug molecules [28].

The objective of this work is to develop TOFs for the delivery of EBT through oral route to achieve improved therapeutic plasma levels. Moreover, the developed transfersomes and TOFs were evaluated for vesicle size distribution, polydispersity index, zeta potential, Fourier-transform infrared spectroscopy (FTIR), X-ray diffraction analysis (XRD), differential scanning calorimetry (DSC), scanning electron microscopy (SEM), 
in vitro drug release and ex vivo permeation, as well as the in vivo pharmacokinetic and pharmacodynamics parameters.

\section{Materials and Methods}

\subsection{Materials}

Phospholipon ${ }^{\circledR} 90 \mathrm{H}$ (phosphatidylcholine; PC) was gifted by Lipoid GmbH (Ludwigshafen, Germany). Ebastine (EBT) was provided by SIMZ Pharmaceuticals (Lahore, Pakistan). Tween-80 ${ }^{\circledR}$ (Polyoxyethylene sorbitan monooleate), Span $20^{\circledR}$ (Sorbitan monolaurate) and HPLC grade organic solvents, including chloroform $\left(\mathrm{CHCl}_{3}\right)$ and methanol $(\mathrm{MeOH})$, were generously donated by Wimits Pharmaceuticals (Lahore, Pakistan). Cellophane membrane with a molecular weight cut-off value of 12,000-14,000 KDa was purchased from Sigma-Aldrich Chemie GmbH (Taufkirchen, Germany). Hydroxypropyl methylcellulose (HPMC-K15M) having methoxy and hydroxypropyl contents of 19-24\% and $7-12 \%$, respectively, as well as glycerol and poly-sucralose, were purchased from Arsons Pharmaceuticals (Lahore, Pakistan). Phosphate buffered saline (PBS) with a pH of 7.4 was prepared freshly, sterile filtered and stored in the fridge for further use. Sterile filtered ultra-pure water (ELGA Lab water, High Wycombe, UK) was used for all the experiments.

\subsection{Preparation of Transfersomes}

Transfersomes (composition given in Table 1) were prepared with the conventional thin film hydration method, as described by Elkomy et al., with slight modifications [29]. Briefly, drug, PC and EAs were dissolved in chloroform/ methanol (2:1) mixture using a round bottle flask (Figure 1). The EBT (10\%) was incorporated into the mass concentration of transfersomal formulations (Table 1). The mass concentration ratio of EBT to the total PC/EA concentration was 1:10. The organic solvents were then removed using a rotary evaporator (Rotavapor R-300, Buchi Labortechnik AG, Flawil, Switzerland) equipped with a vacuum pump at $50{ }^{\circ} \mathrm{C}$. The developed film was hydrated with PBS $(\mathrm{pH}, 7.4)$ by thoroughly agitating and mixing through magnetic stirrer at room temperature for $1 \mathrm{~h}$. Afterwards, the developed vesicles were sonicated for $30 \mathrm{~min}$ in a bath type sonicator (Elmasonic P, Elma Schmidbauer, Singen, Germany). Finally, the obtained transfersomes were further used in the development of TOFs after analysis.

Table 1. Composition of transfersomes formulations. All the formulations contained $10 \% w / w$ EBT.

\begin{tabular}{cccc}
\hline & & \multicolumn{2}{c}{ Edge Activator (\%) } \\
\cline { 3 - 4 } Formulation Code & PC (\%) & Tween $\mathbf{8 0}^{\circledR}$ & Span $^{\circledR} \mathbf{2 0}^{\circledR}$ \\
\hline VT-1 & 95 & 05 & - \\
VT-2 & 90 & 10 & - \\
VT-3 & 85 & 15 & - \\
VT-4 & 80 & 20 & 05 \\
VS-1 & 95 & - & 10 \\
VS-2 & 90 & - & 15 \\
VS-3 & 85 & - & 20 \\
VS-4 & 80 & - & - \\
\hline
\end{tabular}

\subsection{Preparation of TOFs}

The solvent casting method was used for the preparation of oral films with slight modifications [30]. The detailed formulations of TOFs are presented in Table 2. Briefly, the film solutions were prepared by dispersing the HPMC-K15M (2-3\%) and glycerol (4-8\%) in distilled water; subsequently, polysucralose (1\%) was added. The mixture was stirred using a magnetic stirrer at $250 \mathrm{rpm}$ and $25^{\circ} \mathrm{C}$ for $12 \mathrm{~h}$. The transfersomal dispersion containing $10 \mathrm{mg} / \mathrm{mL}$ of EBT was added to the film solution and subjected to homogenization using a Heidolph-4000 (Heidolph Instruments, Schwabach, Germany) for 5 min [31]. The solution was left over night to homogenize and degassed completely. The solution having a viscosity of $7250 \mathrm{mPa} \cdot \mathrm{s}$ was casted with the help of a film applicator (BGD-219, Solvica Advanced 
Testing equipment, Düsseldorf, Germany) on a polyethylene terephthalate (PET) release liner Hostaphan-RN ${ }^{\circledR}$, (Mitsubishi Polyester Film Incorporation, Greer, SC, USA) using a speed of $6 \mathrm{~mm} / \mathrm{s}$. Afterwards, the solvent was allowed to evaporate for $24 \mathrm{~h}$ at room temperature. Polyethylene monolayer CoTran ${ }^{\mathrm{TM}}\left(3 \mathrm{M}^{\mathrm{TM}} \mathrm{GmbH}\right.$, Nordrhein-Westfalen, Germany) was used as backing layer. The films were peeled off and cut into desired sizes and were stored in a desiccator after wrapping in aluminum foil for further analysis [32].

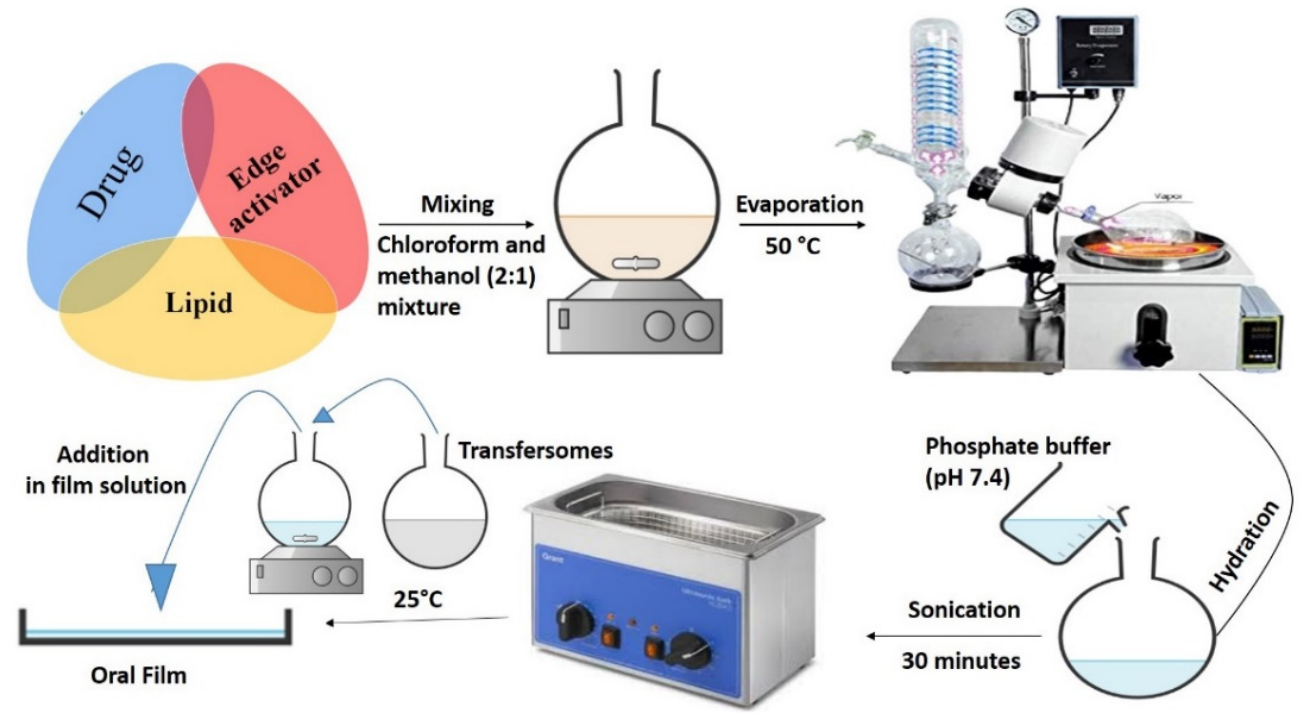

Figure 1. Schematic representation of the transfersomes formulation process.

Table 2. Composition of TOFs (each film contains $10 \mathrm{mg} / \mathrm{mL}$ of EBT).

\begin{tabular}{ccc}
\hline TOFs Formulation & HPMC-K15M (\%) & Glycerol (\%) \\
\hline ETF-1 & 2.0 & 4.0 \\
ETF-2 & 2.5 & 6.0 \\
ETF-3 & 3.0 & 8.0 \\
ETF-4 & 2.0 & 4.0 \\
ETF-5 & 2.5 & 6.0 \\
ETF-6 & 3.0 & 8.0 \\
ETF-7 & 2.0 & 4.0 \\
ETF-8 & 2.5 & 6.0 \\
ETF-9 & 3.0 & 8.0 \\
\hline
\end{tabular}

\subsection{Characterization of Transfersomes}

Particle size distribution and $\zeta$ potential of the developed transfersomes were determined using dynamic light scattering Zetasizer Nano-ZS (Malvern Panalytica GmbH, Kassel, Germany) and laser doppler velocimetry (LDV), respectively. The instrument was equipped with $10 \mathrm{~mW}$ HeNe laser at a wavelength of $633 \mathrm{~nm}$ at $25^{\circ} \mathrm{C}$. The scattered light was detected at an angle of $173^{\circ}$. Measurement position and laser attenuation were automatically adjusted with each measurement. The disposable capillary cell (DTS1060, Malvern Instruments) was used for the measurements. The sample was always diluted with purified water (1:100) before each measurement. The refractive index of water (1.33) and viscosity $(0.88 \mathrm{mPa} \cdot \mathrm{s})$ were taken into account for data analysis. The size distribution of vesicles for homogeneity or heterogeneity was determined from the polydispersity index (PDI). All samples were observed in triplicate with each measurement comprising of 15-100 runs, depending on the sample. Data are expressed as mean \pm s.d.

\subsection{Deformability Studies}

In order to conduct deformability studies, the vesicle dispersion was passed through a polycarbonate membrane filter (Isopore ${ }^{\mathrm{TM}}$, Merck, MA, USA) with a pore size of $30 \mathrm{~nm}$ 
under constant pressure of 1.5 MPa of nitrogen stream for $15 \mathrm{~min}$ [33]. The transfersomal suspension was then collected in a container placed on a balance to note the weight change as a function of time.

\subsection{Entrapment Efficiency (EE\%)}

The EE\% of all the formulations was evaluated to analyze the impact of edge activators and lipids (PC) in drug entrapment [34]. The transfersomes were separated from the free drug by centrifugation at 10,000 rpm for $30 \mathrm{~min}$ and $4{ }^{\circ} \mathrm{C}$ using an Eppendorf centrifuge 4518 (Eppendorf, Hamburg, Germany). To remove the excess drug from the outer surface, the separated transfersomes were washed with PBS $(\mathrm{pH}, 7.4)$ three times. The free drug was measured using a Shimadzu-HPLC-LC-10AD (Shimadzu Corporation, Kyoto, Japan) at a wavelength of $257 \mathrm{~nm}$. The EE \% was calculated using the following equation [35]:

$$
\mathrm{EE}(\%)=\frac{\mathrm{Q}_{\mathrm{t}}-\mathrm{Q}_{\mathrm{u}}}{\mathrm{Q}_{\mathrm{t}}} \times 100
$$

where $Q_{t}$ is the total quantity of drug added and $Q_{u}$ is the quantity of free drug in the transfersomes.

\subsection{Characterization of TOFs}

2.7.1. Viscosity Measurement of Film Solutions

A digital Brookfield ${ }^{\circledR}$ Viscometer-DV2T (Brookfield Ametek, Middleborough, MA, USA) was coupled with a S-18 spindle to determine the viscosity of the TOF solution at a speed of $10 \mathrm{rpm}$. Triplicate readings of all film solutions were taken at $25 \pm 2{ }^{\circ} \mathrm{C}$ [36].

\subsubsection{Film Thickness and Weight}

The mean thickness of the film was measured at three different points using a standard size piece $\left(2 \times 2 \mathrm{~cm}^{2}\right)$ for each film with the help of a digital micrometer Mitutoyo 500-19630 (Mitutoyo Corporation, Kawasaki, Kanagawa, Japan). Besides, the average weight of the films was recorded using an analytical balance (Cubis-MSA-225P, Sartorius, Aubagne, France) [37].

\subsubsection{Surface $\mathrm{pH}$}

The surface of each film was moistened with distilled water in a petri dish for $1 \mathrm{~min}$ and $\mathrm{pH}$ was measured by placing an electrode of a Benchtop $\mathrm{pH}$ meter-S210 (MettlerToledo International Incorporation, Columbus, OH, USA) on the surface of the film. The $\mathrm{pH}$ for three independent films was measured and the average was determined. Data are expressed as mean \pm s.d. [38].

\subsubsection{Folding Endurance}

The endurance of films was considered as a measure of fold numbers. Films with size of $4 \times 4 \mathrm{~cm}^{2}$ were repeatedly folded at the same point until broken. The number of folds of each film was recorded as endurance value [39].

\subsubsection{Tensile Strength and \% of Elongation of TOFs}

The tensile strength of films was measured by attaching films of $2 \times 2 \mathrm{~cm}^{2}$ size with the grips of a tensile strength analyzer Shimadzu-AGS-100kNX (Shimadzu Corporation, Kyoto, Japan). The force required to move the grip away till the film ruptured was noted as tensile strength. Further, the \% of elongation was also calculated [40].

\subsubsection{Moisture Content of TOFs}

The weight of films before and after drying were recorded to calculate the water loss from oral films [41]. The film of approximately $2 \times 2 \mathrm{~cm}^{2}$ in size was cut and weighed. This was nominated as initial weight $\left(W_{1}\right)$. Then, the same film was placed in a hot dry oven with temperature maintained at $50 \pm 1{ }^{\circ} \mathrm{C}$ for $1 \mathrm{~h}$. After taking it out of the oven, the 
dried film was weighed again and that was considered its final weight $\left(\mathrm{W}_{2}\right)$. The water loss was calculated using following equation:

$$
\text { Water loss }(\%)=\frac{W_{1}-W_{2}}{W_{1}} \times 100
$$

where $W_{1}$ is the initial weight of the film and $W_{2}$ is the final weight of the film.

\subsubsection{Content Uniformity}

The content uniformity of the oral films was determined using solvent extract techniques. Briefly, a film of $2 \times 2 \mathrm{~cm}^{2}$ in size was dissolved in $20 \mathrm{~mL}$ of methanol. The solution was filtered through an MF-Millipore ${ }^{\mathrm{TM}}$ membrane filter having a pore size of $0.45 \mu \mathrm{m}$ (Merck, Boston, MA, USA) to remove undissolved matter. Subsequently, different dilutions were prepared to be analyzed with a UV/VIS spectrophotometer (UV mini 1240, Shimadzu, Japan) at $254 \mathrm{~nm}$ wavelength. The content uniformity was then determined using calibration curve already constructed in the same solvent system with known EBT concentrations. The films without drug were taken as blank control [42].

\subsubsection{Reconstitution of TOFs}

The double distilled water was added to reconstitute the films to confirm the colloidal solution. The oral film was re-dispersed in $1 \mathrm{~mL}$ of distilled water/buffer solution, $\mathrm{pH}$ of 6.8, following a previously published method [43]. The solution was stirred for $1 \mathrm{~h}$. After reconstitution, the solution was analyzed for entrapment efficiency, particle size and deformability of transfersomes [44].

\subsubsection{Fourier-Transform Infrared Spectroscopy (FTIR)}

The FTIR spectra of EBT, PC, Tween $80^{\circledR}$, Span $20^{\circledR}$ and the optimized formulation (i.e., ETF-5) were performed between 500 and $4000 \mathrm{~cm}^{-1}$ wavenumbers using an Agilent FTIR-Cary-360 (Agilent Scientific Instruments, Santa Clara, CA, USA) [45].

\subsubsection{Powder X-ray Diffraction (PXRD)}

PXRD studies of pure drug and TOFs were conducted using a diffractometer, D8advance (Bruker Corporation, Billerica, MA, USA). The samples were measured between the angles of 5 and $50^{\circ}$ at $2 \theta$ [46].

\subsubsection{Differential Scanning Calorimetry (DSC)}

The DSC analysis of pure drug, lipids and edge activators were performed using a simultaneous Thermal Analyzer SDT-Q600 (TA Instruments, New Castle, DE, USA), at a temperature scanning rate of $10^{\circ} \mathrm{C} / \mathrm{min}$ and nitrogen flow rate of $20 \mathrm{~mL} / \mathrm{min}$. The samples were run between 25 and $200{ }^{\circ} \mathrm{C}$ to perform DSC tests [47].

\subsubsection{Scanning Electron Microscopy (SEM)}

In order to study the surface morphology of the films, the developed formulations were subjected to scanning electron microscopy using a Nova-Nano-SEM-450, (FEI, Hillsboro, OR, USA). The samples of pure drug and the prepared films were positioned on a copper grid and the surface texture was examined [46].

\subsubsection{Atomic Force Microscopy (AFM)}

The surface texture of oral film was analyzed by the atomic force microscopy DimensionXR SPM (Bruker Corporation, Billerica, MA, USA), using an etched silicon probe at tapping mode (i.e., intermittent contact mode). The dry film was placed on a glass stub and subjected to analysis. The oral film of $5 \times 5 \mu \mathrm{m}^{2}$ in size was examined at a $0.9 \mathrm{~Hz}$ scanning rate to measure its height from different points [48]. 


\subsubsection{In Vitro Drug Release}

The USP paddles apparatus (Biobase Biodustry, Jinan, Shandong China) was used to study in vitro drug release from the developed TOFs. Briefly, an in vitro release study was performed in $0.1 \mathrm{~N} \mathrm{HCl}(\mathrm{pH}, 1.2)$ for $2 \mathrm{~h}$ and in phosphate buffer $(\mathrm{pH}, 6.8)$ for $24 \mathrm{~h}$. Approximately $500 \mathrm{~mL}$ of $0.1 \mathrm{~N} \mathrm{HCl}(\mathrm{pH}, 1.2) / \mathrm{PBS}(\mathrm{pH}, 6.8)$ was poured in dissolution vessels. The film size was cut per unit dose and placed in a steel wire mesh. Then mesh was tied with paddles. The temperature was kept at $37 \pm 0.5^{\circ} \mathrm{C}$ and stirring speed was adjusted at $100 \mathrm{rpm}$. The samples $(5 \mathrm{~mL})$ were drawn at predetermined time intervals $(0$, $1,2,3,4,5,6,8$ and $24 \mathrm{~h}$ ) and fresh dissolution medium was added every time a sample was taken to maintain the sink conditions. The drug release was analyzed using ShimadzuHPLC-LC-10AD (Shimadzu Corporation, Kyoto, Japan) at $257 \mathrm{~nm}$ [29]. The mobile phase was composed of an acetonitrile:methanol:ammonium acetate buffer (20:30:50) and was equipped with a C-18 column ( $5 \mathrm{~mm}, 25,034.0 \mathrm{~mm}$; Agilent). The flow rate of $1 \mathrm{~mL} / \mathrm{min}$ and column temperature of $40{ }^{\circ} \mathrm{C}$ were maintained throughout analysis.

\subsubsection{Ex Vivo Permeation}

Ex vivo permeation of EBT from the optimized formulation ETF- 5 was determined by vertical Franz diffusion cells. The Wistar rats were euthanized, their small intestines were separated and washed several times with normal saline. Subsequently, a small intestine was placed in PBS $(\mathrm{pH}, 7.4)$ at a temperature of $37 \pm 1{ }^{\circ} \mathrm{C}$. The ileum membrane of the small intestine was used as a permeation barrier with a permeation area of approximately $1.76 \mathrm{~cm}^{2}$. The receptor chamber was filled with $7 \mathrm{~mL}$ of PBS (pH, 7.4). The temperature of PBS was maintained at $37 \pm 1{ }^{\circ} \mathrm{C}$, whereas the stirring speed was adjusted to $100 \mathrm{rpm}$. At scheduled time points, a $0.2 \mathrm{~mL}$ sample was withdrawn from the receptor compartment using a micropipette. The amount of drug permeated through part of the small intestine was determined using Shimadzu-HPLC-LC-10AD (Shimadzu Corporation, Kyoto, Japan) equipped with a C-18 column ( $5 \mathrm{~mm}, 25,034.0 \mathrm{~mm}$; Agilent) at $257 \mathrm{~nm}$ using an acetonitrile:methanol:ammonium acetate buffer (20:30:50) as mobile phase. The rate of permeation (i.e., flux) was calculated by plotting percentage of drug permeated per unit surface area against time [49]:

$$
\text { Steady state flux }\left(\mathrm{J}_{\mathrm{ss}}\right)\left(\mu \mathrm{g} / \mathrm{cm}^{2} / \mathrm{h}\right)=\frac{\text { Permeation rate }}{\text { Per unit surface area }}
$$

\subsubsection{Compliance with Ethical Standards}

All animal studies were approved by the Institutional Review Board and bioethical committee of the Government College University Faisalabad (Ref No. GCUF/ERC/2068, Study No. 19668, IRB No. 668, dated 5 September 2019). Wistar rats weighing 150-210 g aged 3-4 months were placed separately in steel cages filled with wood dust (replaced every $24 \mathrm{~h}$ ). The rats were housed in a controlled environment (temperature, $22 \pm 2{ }^{\circ} \mathrm{C}$; humidity, $60 \pm 10 \%$, with an alternate $12 \mathrm{~h} \mathrm{light/dark} \mathrm{cycle)} \mathrm{for} \mathrm{a} \mathrm{week} \mathrm{before} \mathrm{and} \mathrm{throughout} \mathrm{all}$ experiments. All the animals were provided free access to tap water and commercial laboratory feed ad libitum (Hi-Tech Feeds Pvt. Ltd., Lahore, Pakistan). Appropriate care was exercised to minimize the number of animal used as defined by the $3 R$ principle, i.e., replacement, reduction and refinement. The study was carried out in strict compliance with the institutional guidelines and the recommendations of the "Guide for the care and use of laboratory animals, institute of laboratory animal resources".

\subsubsection{In Vivo Pharmacokinetic Study}

TOFs, plain film (loaded with crystalline EBT) and pure EBT suspension were evaluated for pharmacokinetic parameters in male Wistar rats. Randomly, the rats were divided in three groups $(\mathrm{E}, \mathrm{P}$ and $\mathrm{T})$, each having 6 rats $(\mathrm{n}=6)$. Samples were administered orally to all the animals of the three groups. The EBT dose in each treatment was equivalent to $10 \mathrm{mg} / \mathrm{kg}$ body weight. The ether anesthesia was given to all rats for the placement of TOFs in the oral cavity. The oral films were cut into $4 \times 4 \mathrm{~mm}^{2}$ pieces (each piece 
contained almost $2 \mathrm{mg}$ of EBT) and placed in the oral cavity with the help of a Teflon spatula and forceps and subsequently swallowed with water. The films were intact when they were administered to the rats. Blood samples were withdrawn from the tail vein at predetermined time intervals $(0.5,1,2,3,4,5,6,8,10,12,24,48$ and $72 \mathrm{~h})$. Blood samples collected in heparinized plastic tubes were subjected to centrifugation (Centurion Scientific, Chichester, UK) at $1500 \mathrm{rpm}$ for $5 \mathrm{~min}$. The plasma was carefully pipetted out and stored in Eppendorf plastic tubes at $-20^{\circ} \mathrm{C}$ for further analysis.

\subsubsection{Extraction of EBT and Carebestine from Plasma}

Equal quantities of plasma and absolute methanol were centrifuged at 10,000 rpm for $5 \mathrm{~min}$. Nitrogen stream was applied $\left(-40^{\circ} \mathrm{C}\right)$ to dry the supernatant. The obtained residue was reconstituted with methanol and centrifuged at 10,000 rpm to collect the supernatant for further analysis using reverse phase isocratic HPLC Shimadzu, LC-10AD, (Shimadzu Corporation, Kyoto, Japan).

\subsubsection{HPLC Analysis and Pharmacokinetic Parameters}

The mobile phase was composed of acetonitrile:methanol:ammonium acetate buffer (20:30:50). To analyze EBT and carebastine in samples, the isocratic reverse phase ShimadzuHPLC-LC-10AD (Shimadzu Corporation, Kyoto, Japan) equipped with a C-18 column $(4.6 \times 250 \mathrm{~mm}$; Agilent) was run at $257 \mathrm{~nm}$ wavelength using flow rate of $1 \mathrm{~mL} / \mathrm{min}$. The temperature of the column was fixed at $40^{\circ} \mathrm{C}$. The final concentrations of standard and sample $(40 \mu \mathrm{g} / \mathrm{mL})$ were prepared. After setting baseline, the samples were injected for elution. The Microsoft Excel PK Solver ${ }^{\mathrm{TM}}$ (version 2016) software was used to calculate maximum plasma concentration $\left(\mathrm{C}_{\max }\right)$, time to reach maximum plasma concentration $\left(\mathrm{T}_{\max }\right)$ and elimination half-life $\left(\mathrm{K}_{\mathrm{e}}\right)$, as well as the area under the plasma concentrationtime curve $\left(\mathrm{AUC}_{0-\mathrm{t}}\right)$.

\subsubsection{In Vivo Pharmacodynamics (Histamine Induced Wheal and Flare Challenge)}

Rats were divided into four groups each comprising of 6 rats $(n=6)$. The site for histamine-induced skin reaction was prepared. Histamine epi-cutaneous injection $(0.05 \mathrm{~mL}$ of $100 \mu \mathrm{g} / \mathrm{mL}$ ) was used to induce wheal and flare in all groups and the gap between the testing points was kept at $3 \mathrm{~cm}$. The time points for wheal measurement were designated as $0,4,8$ and $24 \mathrm{~h}$. Single dose was administered to the rats in all groups except placebo. The area of wheal and flare was noted by tracing on a paper after $15 \mathrm{~min}$ of histamine injection. Diameter of wheal and flares was noted, based on an angle of $90^{\circ}$. The wheal and flare were measured at predetermined time intervals to evaluate the treatment efficiency of developed TOFs with reference to pure drug and the plain films. In addition, the animals were observed for any adverse effects during the study.

$$
\begin{gathered}
\text { Area }=\frac{\pi \times D_{L} \times D_{s}}{4} \\
A=\pi(R)^{2} \\
\text { Wheal area reduction }(\%)=100-\left(\frac{A_{t}}{A_{b}}\right) \times 100
\end{gathered}
$$

where, $D_{L}$ is the maximum wheal diameter and $D_{S}$ is the minimum wheal diameter; $A$ is the area of wheal and $R$ is the radius of wheal; $A_{b}$ is the area before treatment and $\left(A_{t}\right)$ is the area after treatment.

\subsection{Statistical Analysis}

The SPSS ${ }^{\circledR}$ software (version 21) was used to apply one-way ANOVA to in vitro drug release, ex vivo permeation and in vivo pharmacokinetic data, followed by a posthoc Tukey's test. A $p$-value $<0.05$ was considered statistically significant for population difference among groups. 


\section{Results}

\subsection{Physicochemical Characterizations}

The EBT loaded transfersomes were characterized to evaluate their physiochemical properties. The size of all formulations was found in the range from $66.3 \pm 4.3$ to $88.7 \pm 2.8 \mathrm{~nm}$ with the polydispersity index ranging from 0.014 to 0.21 . The surface charge of developed transfersomes was detected between $-27.4 \pm 2.14$ and $-37.7 \pm 3.1 \mathrm{mV}$ (Figure 2A). The EE (\%) of all formulations was more than $90 \%$ (Figure $2 \mathrm{~B}$ ). The transfersomal formulation VS-3 showed the highest deformability value $(18.52 \mathrm{mg} / \mathrm{s})$; hence, it was selected, based on its high deformability value, to be integrated into oral films.

\section{A}

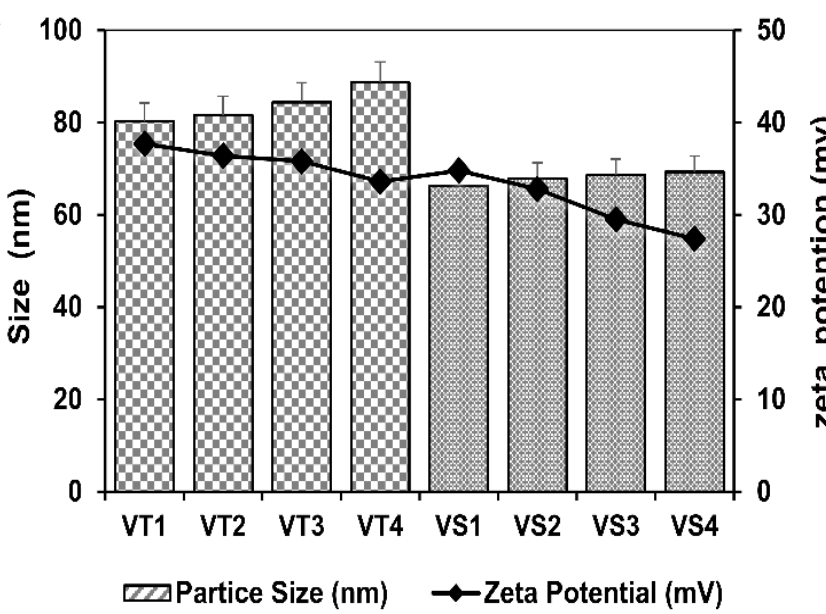

B

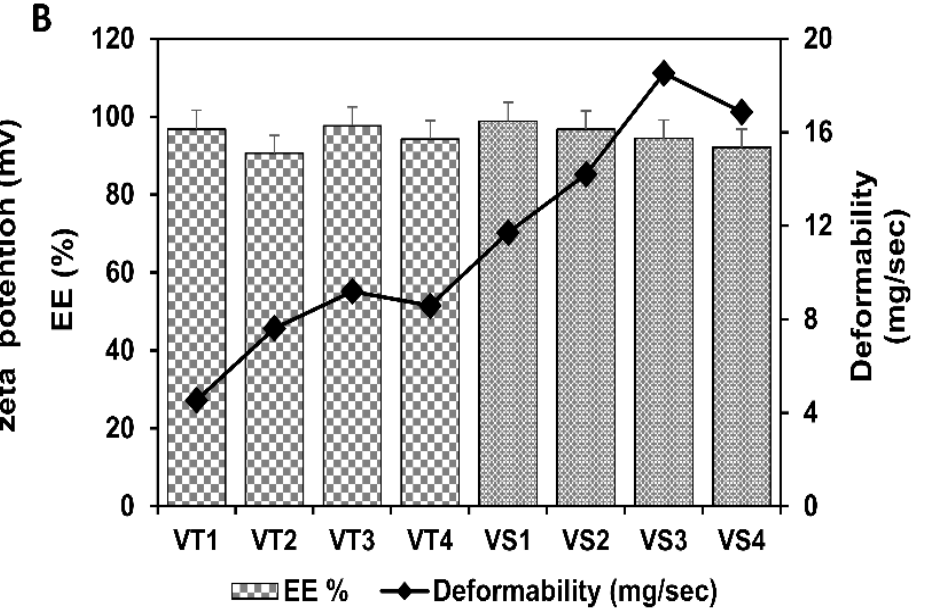

Figure 2. Transfersomes (A) size and charge, (B) entrapment efficiency and deformability.

\subsection{Characterization of TOFs}

Table 3 shows characterization results of TOFs. The high rheology of film solution (from 6900 to $7400 \mathrm{mPa} . \mathrm{s}$ ) was obtained from HPMC in the presence of the permeation enhancer and plasticizer for the development of oral films. TOFs appeared to be smooth, flexible and uniform. Films weight ranged from $157.4 \pm 2.64$ to $192.1 \pm 1.15 \mathrm{mg}$ and the average surface $\mathrm{pH}$ was approximately 6.8. The thickness of films was between $0.241 \pm 0.03$ and $0.387 \pm 0.02 \mathrm{~mm}$. ETF-5 formulation provided the best folding durability, with a tensile strength above $36.4 \mathrm{MPa}$. The elongation percentage of the films ranged between $4.1 \pm 0.16$ and $17.9 \pm 0.31 \%$. The content uniformity was found within specification (99-102\%). Out of all developed film formulations, the ETF-5 film was chosen for further studies on the criterion of efficacious physiochemical presentation with minimal amounts of film-former and plasticizer.

Table 3. Results of TOFs for thickness, weight, folding endurance, tensile strength and \% elongation.

\begin{tabular}{cccccc}
\hline $\begin{array}{c}\text { TOF } \\
\text { Formulations }\end{array}$ & $\begin{array}{c}\text { Thickness } \\
(\mathbf{m m}) \pm \mathbf{S D}\end{array}$ & $\begin{array}{c}\text { Weight } \\
\mathbf{( m g )} \pm \mathbf{S D}\end{array}$ & $\begin{array}{c}\text { Folding Endurance } \\
\mathbf{( n )} \pm \mathbf{S D}\end{array}$ & $\begin{array}{c}\text { Tensile Strength } \\
\mathbf{( M p a )} \pm \mathbf{S D}\end{array}$ & $\begin{array}{c}\text { Elongation } \\
\mathbf{( \% )} \pm \mathbf{S D}\end{array}$ \\
\hline ETF-1 & $0.35 \pm 0.21$ & $57.4 \pm 2.64$ & $21 \pm 2.73$ & $43 \pm 1.24$ & $4.1 \pm 0.16$ \\
ETF-2 & $0.25 \pm 0.11$ & $69.5 \pm 2.55$ & $27 \pm 1.42$ & $56 \pm 1.53$ & $5.4 \pm 0.31$ \\
ETF-3 & $0.26 \pm 0.06$ & $87.1 \pm 3.60$ & $29 \pm 2.51$ & $67 \pm 2.29$ & $6.8 \pm 0.12$ \\
ETF-4 & $0.24 \pm 0.24$ & $61.4 \pm 1.42$ & $34 \pm 1.18$ & $82 \pm 3.22$ & $8.2 \pm 0.26$ \\
ETF-5 & $0.27 \pm 0.04$ & $76.2 \pm 1.27$ & $38 \pm 1.45$ & $96 \pm 1.32$ & $9.5 \pm 0.12$ \\
ETF-6 & $0.36 \pm 0.06$ & $88.0 \pm 3.30$ & $38 \pm 4.54$ & $107 \pm 2.14$ & $10.9 \pm 0.18$ \\
ETF-7 & $0.34 \pm 0.12$ & $62.3 \pm 1.37$ & $39 \pm 3.93$ & $76 \pm 3.51$ & $12.7 \pm 0.28$ \\
ETF-8 & $0.36 \pm 0.34$ & $77.9 \pm 1.24$ & $41 \pm 2.67$ & $118 \pm 1.04$ & $14.8 \pm 0.21$ \\
ETF-9 & $0.39 \pm 0.26$ & $92.1 \pm 1.15$ & $46 \pm 4.88$ & $137 \pm 0.29$ & $17.9 \pm 0.31$ \\
\hline
\end{tabular}




\subsection{Reconstitution of TOFs Containing Transfersomes}

The EE \% was found to be $94 \%$ after reconstitution of the optimized formulation ETF-5. The particle size and deformability were $68.8 \pm 0.13 \mathrm{~nm}$ and $18.4 \pm 0.11 \mathrm{mg} / \mathrm{s}$, respectively. In addition, $\mathrm{EE} \%$, particle size and deformability were comparable with the original results. It supported that the properties of transfersomes remained intact upon incorporation into oral films.

\subsection{Fourier-Transform Infrared Spectroscopy (FTIR)}

The FTIR spectrum of pure EBT showed major peaks at $3050 \mathrm{~cm}^{-1}, 2945 \mathrm{~cm}^{-1}$, $1452 \mathrm{~cm}^{-1}, 1270 \mathrm{~cm}^{-1}$ and $1674 \mathrm{~cm}^{-1}$ wavenumbers, as shown in Figure 3. The phosphatidylcholine $\mathrm{C}=\mathrm{O}$ stretching appeared at $1704 \mathrm{~cm}^{-1}$, due to the ester group. The phosphate stretch appeared at $1061 \mathrm{~cm}^{-1}$ and $\mathrm{P}=\mathrm{O}$ vibration at $1251 \mathrm{~cm}^{-1}$. In addition, the Tween $80^{\circledR} \mathrm{C}=\mathrm{O}$ stretch was seen at $1731 \mathrm{~cm}^{-1}, \mathrm{C}-\mathrm{H}$ stretching at $2920 \mathrm{~cm}^{-1}$ and $2812 \mathrm{~cm}^{-1}$. In the Span $20^{\circledR}$ IR spectra, the $\mathrm{C}=\mathrm{O}$ stretch appeared at $1735 \mathrm{~cm}^{-1}$ and $\mathrm{C}-\mathrm{H}$ stretch at $2842 \mathrm{~cm}^{-1}$ and $2924 \mathrm{~cm}^{-1}$. Overall, the FTIR spectra of TOF clearly matched with the main peaks of the pure drug. In ETF-5, the $\mathrm{C}-\mathrm{H}$ stretching of ring, $\mathrm{C}-\mathrm{H}$ stretching of $\left(\mathrm{CH}_{3}\right), \mathrm{C}=\mathrm{C}$ stretching aromatic ring, $\mathrm{C}-\mathrm{N}$ stretching and $\mathrm{C}=\mathrm{O}$ stretching were found at same wavenumbers, parallel to pure EBT.

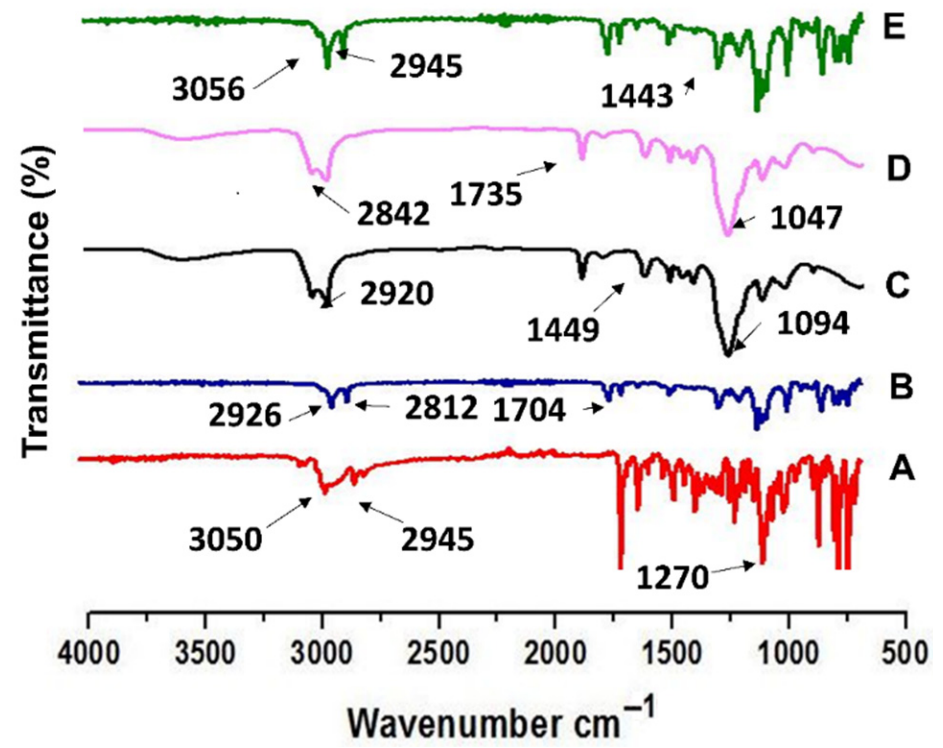

Figure 3. FTIR spectra of (A) EBT, (B) PC, (C) Tween $80^{\circledR}$, (D) Span $20^{\circledR}$ and (E) optimized formulation ETF-5.

\subsection{Morphological Evaluations Using SEM}

The SEM results provided an irregular, rod-shaped and rough crystalline structure of the pure drug (Figure 4A). EBT crystals displayed length and width of varying sizes. The crystals had infinite shape with coarse surface. In comparison, the surface of TOFs was overall uniform, with minute uneven texture (Figure 4B). Further, small size transfersomes embedded on the surface of film appeared round in shape. It could be seen that most transfersomes were confined in the film. The shape of the crystals was changed from plane lamellar to circular shape in form of transfersomes. The SEM results showed that the transfersomes in TOFs successfully converted EBT crystals to amorphous form.

\subsection{Atomic Force Microscopy (AFM)}

The height of films from different points were used to describe the morphological characteristics and roughness of the developed TOFs. The calculated average height of film was $271.19 \pm 11.7 \mathrm{~nm}$, after measuring from three different points. The slight fluctuation in the height of film could be attributed to the presence of transfersomes and different 
components in the film; however, the overall film surface was considered smooth. The AFM results confirmed incorporated transfersomes sizes to be in the nano range in TOFs. The penetration of transfersomes in film can be visualized in Figure 5. Moreover, the scanning of film was performed horizontally in lift mode to obtain deflection view. Attractive forces were found between transfersomes and polymers of the film that embedded the transfersomes in the film. The small particle appearance in the deflection image was representative of the size of transfersomes based on force-distance curves.
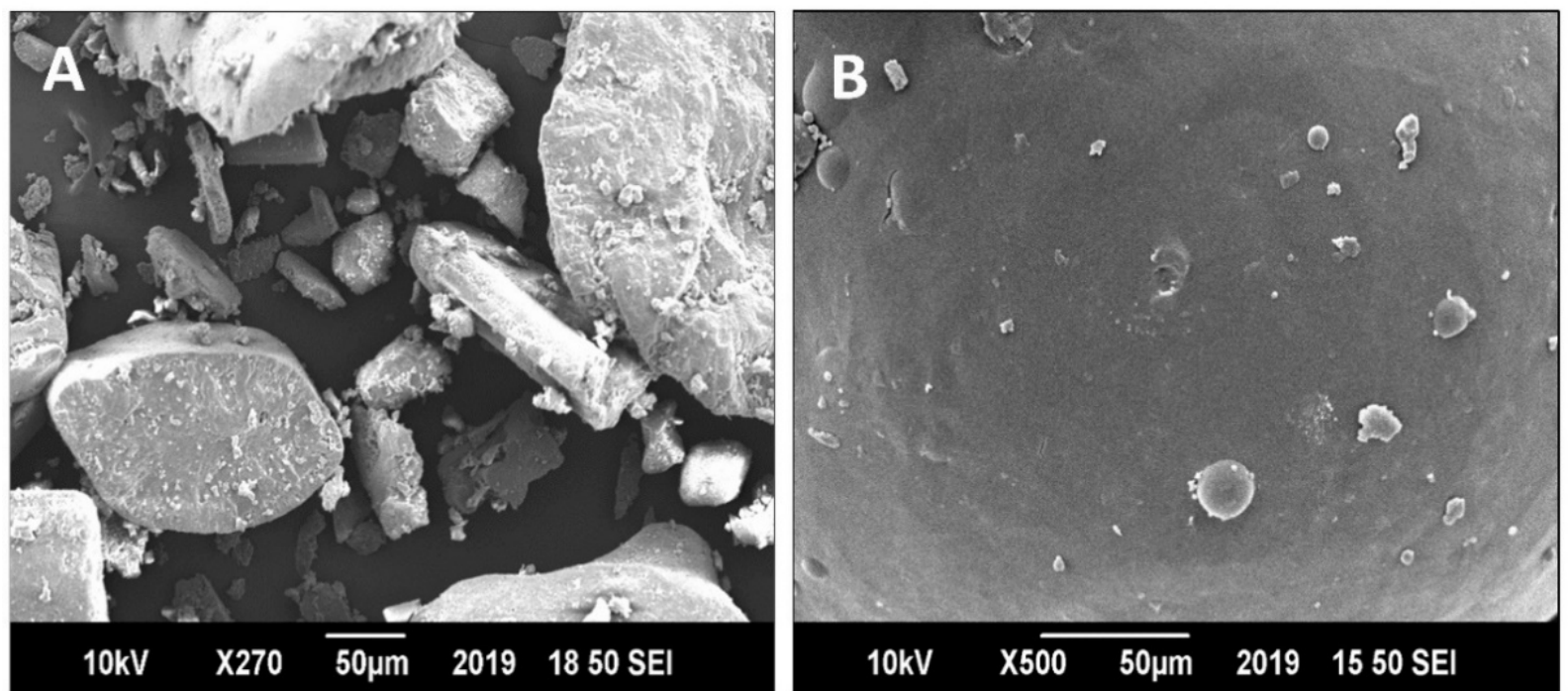

Figure 4. Scanning electron microscopy photographs of (A) EBT and (B) ETF-5 film.

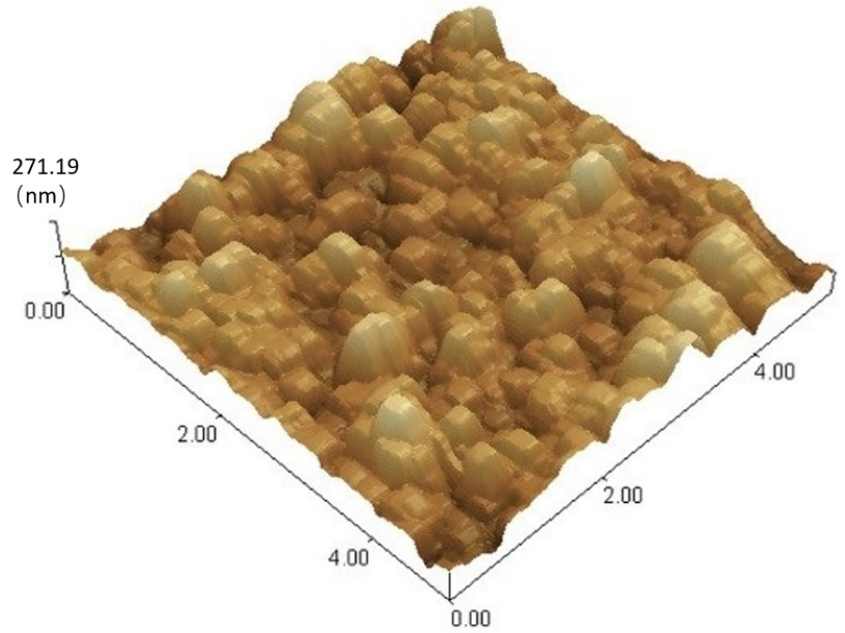

$5.00 \times 5.00(\mu \mathrm{m}) \mathrm{Z} 0.00-271.19(\mathrm{~nm})$

Figure 5. Illustration of surface morphology of optimized formulation (ETF-5) of transfersomesloaded oral films (TOFs).

\subsection{Powder X-ray Diffraction (PXRD)}

The spectra of pure drug revealed numerous diffraction peaks with high intensities at $16.6^{\circ}, 18.8^{\circ}$ and $19.4^{\circ}$, reflecting its crystalline nature (Figure 6A). On the other hand, XRD patterns of TOFs were completely different from those of pure drug, which might be ascribed to its conversion into amorphous form in transfersomes (Figure 6B). In the ETF-5 diffractogram, a few minor peaks were found that may be attributed to film polymers. The absence of large ETF-5 diffractogram peaks, such as $16.6^{\circ}, 18.8^{\circ}$ and $19.4^{\circ}$, indicates that either EBT was converted into amorphous form or completely enclosed in HPMC film. 


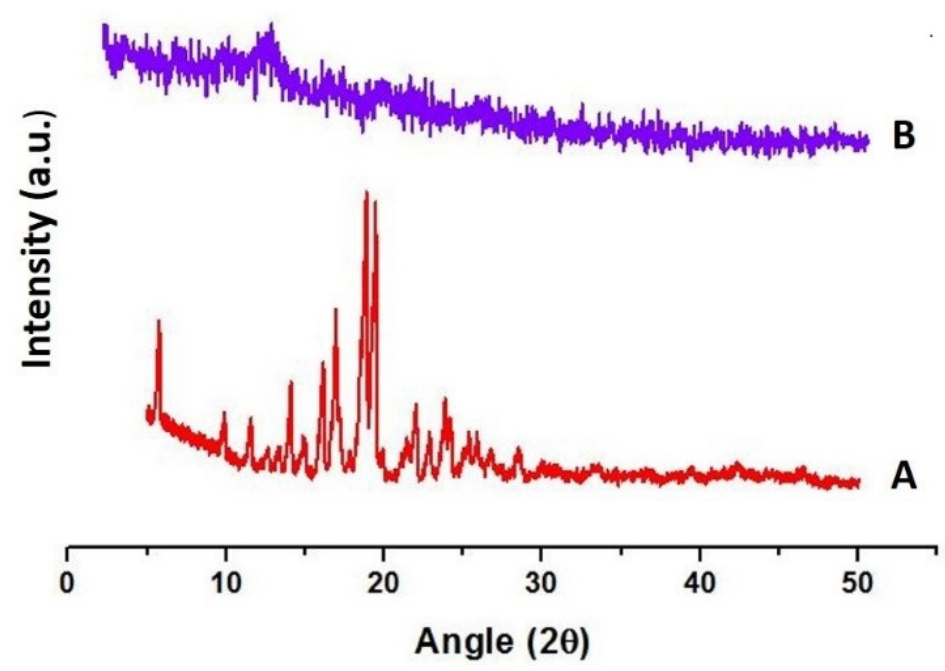

Figure 6. Powder X-ray diffraction of (A) EBT and optimized formulation (B) ETF-5.

\subsection{Differential Scanning Calorimetry (DSC)}

In DSC measurements, the pure drug exhibited a sharp melting endothermic peak at $82{ }^{\circ} \mathrm{C}$, which was not present in the thermogram of the optimized formulation (i.e., ETF-5), indicating the conversion of crystalline drug into amorphous form (Figure 7). The components of transfersomes and oral films played a role in the conversion of the crystal structure of EBT into amorphous form. In ETF-5, the melting endotherm was invisible, which indicated amorphous drug containment in the transfersomes and HPMC film. In addition, the ETF-5 thermogram showed no sign of a dehydration peak, glass transition temperature $(\mathrm{Tg})$ peak and endothermic peak, which supports the non-crystalline state of EBT.

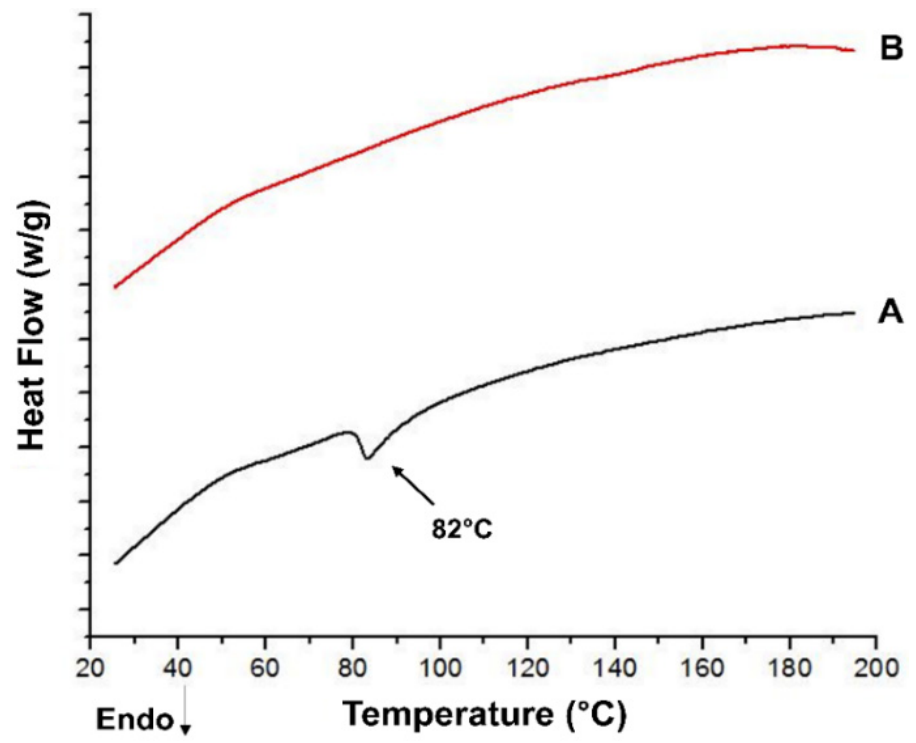

Figure 7. DSC thermograms of (A) EBT and (B) oral film loaded with optimized transfersomes (ETF-5-TOFs).

\subsection{In Vitro Drug Release Studies}

A significant difference was observed in statistical calculations of release pattern of the transfersomal formulations $(p<0.05)$. The drug release from all the formulations followed zero order kinetics $\left(r^{2}=0.98\right)$. The drug release from ETF-5 followed controlled release as the value of the release exponent $(n)$ was greater than 1, while EBT plain film followed the Fickian diffusion mechanism $(n<0.5)$ in the Korsmeyer-Peppas model. 
The rate of dissolution from TOFs was significantly increased, in contrast to the pure drug (Figure 8$)(\mathrm{p}<0.05)$. For instance, only $37 \pm 1.8 \%$ of drug was released in $6 \mathrm{~h}$ and around $48 \pm 3.1 \%$ in $24 \mathrm{~h}$ from crystalline drug suspension. In comparison, more than $52 \pm 2.4 \%$ of drug was released in the first $6 \mathrm{~h}$ and about $82 \pm 1.5 \%$ in $24 \mathrm{~h}$ from ETF-5 formulation. In comparison, drug release from plain film (loaded with crystalline drug) was greater than that of pure drug. The order of cumulative drug release was found as EBT $<$ plain film $<$ ETF-5 $(p<0.05)$. ETF-5 greatly improved the release profile of EBT relative to pure EBT and plain film.

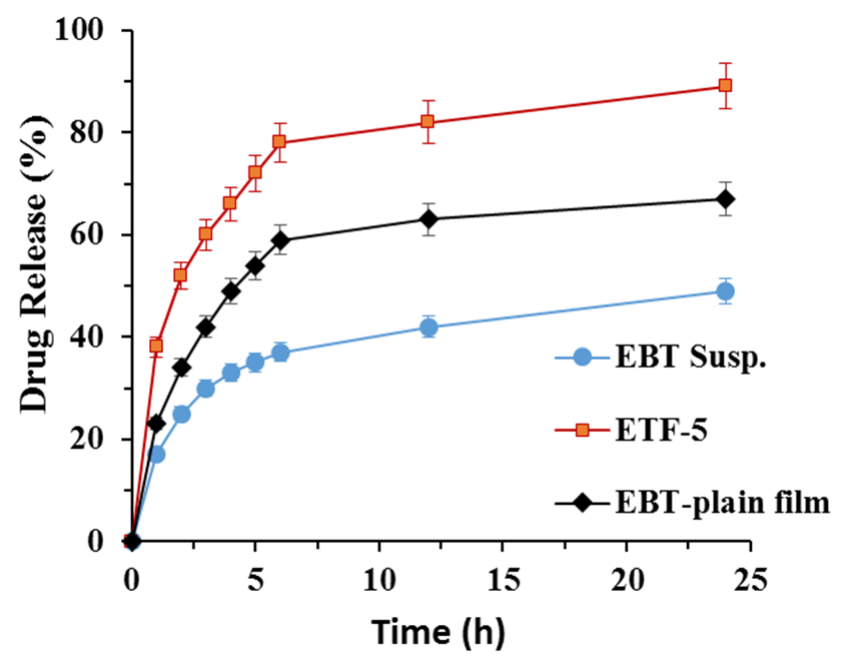

Figure 8. Cumulative in vitro drug release (\%) from EBT suspension, EBT plain film and optimized formulation ETF-5.

\subsection{Ex Vivo Permeation Studies}

The cumulative drug permeated through membrane from EBT suspension was found to be $21.93 \pm 3.67 \%$, while it was $34.55 \pm 2.84 \%$ from EBT-HPMC-K15M plain film $(p<0.05)$. In addition, the cumulative EBT permeated through membrane from ETF-5 was $62.82 \pm 1.53 \%(p<0.05)$. The cumulative drug permeated from the ETF- 5 was expressively greater relative to plain film $(p<0.05)$. The amount of drug permeated by ETF- 5 was 2.86-fold higher than pure drug and 1.81-fold higher than plain film (Figure 9) $(p<0.05)$. Furthermore, the highest permeation flux obtained was $1.96 \mu \mathrm{g} / \mathrm{cm}^{2} / \mathrm{h}$ from ETF- 5 . The order of drug permeation through membrane was of the following order: ETF- $5>$ plain film $>$ EBT suspension. In addition, the model dependent kinetic method was applied to the permeability results of the EBT suspension, plain film and TOFs. The results found were a good fit to zero order kinetics $\left(R^{2} 0.997\right)$. The highest correlation coefficient $\left(R^{2}>0.973\right)$ was obtained through the Higuchi model for pure suspension, plain film and TOFs. The $\mathrm{n}$ values of Korsmeyer-Peppas model showed that plain film followed Fickian (Quasi) diffusion $(n<0.45)$. TOFs followed non-Fickian (anomalous) diffusion $(n=0.89)$.

\subsection{In Vivo Pharmacokinetics}

The EBT concentration was determined in the plasma of rats after single oral dose administration. EBT was converted to its active metabolite carebastine through extensive first-pass metabolism. The mean plasma concentration of carebastine after the administration of pure drug, plain film and ETF-5 are displayed in Figure 10. Oral EBT suspension exhibited $C_{\max }$ after $4.6 \mathrm{~h}$, whereas $C_{\max }$ of plain film appeared after $4.1 \mathrm{~h}$ (Table 4 ). In contrast, the ETF- 5 showed peak plasma concentration after $7.8 \mathrm{~h}$. The ETF- 5 exhibited extended drug absorption, compared to pure drug. The $\mathrm{T}_{\max }$ of pure drug was smaller than that of both films $(p<0.05)$. The area under curve (AUC) of ETF- 5 was significantly higher than those of oral suspension $(p<0.05)$ and the plain film. The results of the AUC were statistically significant, based on differences among comparative products. 


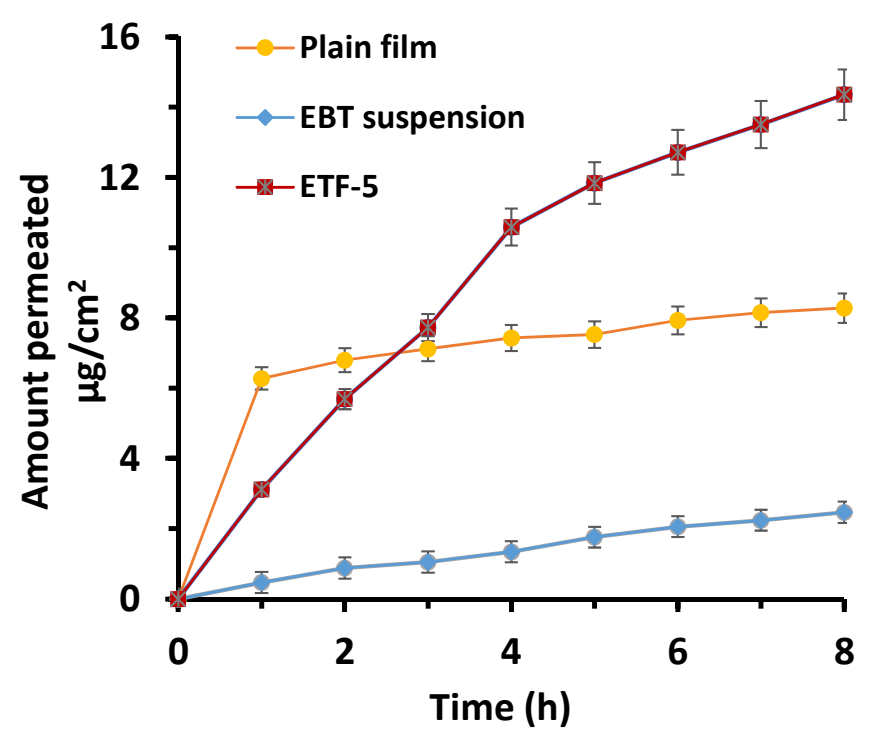

Figure 9. Ex vivo permeation studies of EBT suspension, EBT plain film and ETF-5 formulation.

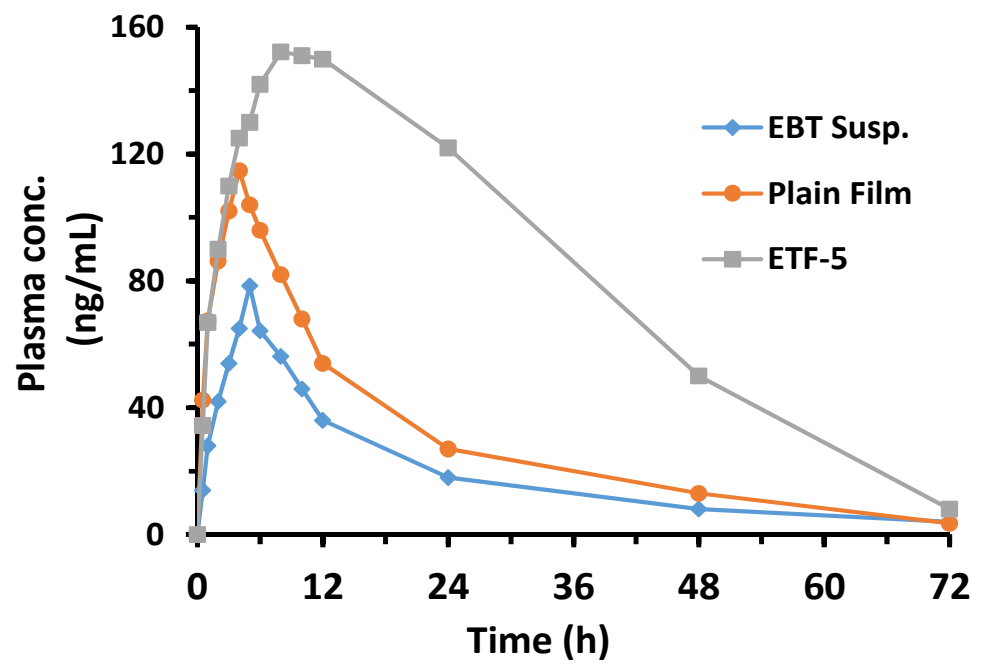

Figure 10. Mean plasma concentration-time profile for carebastine following oral treatment of EBT suspension, EBT plain film and ETF5.

Table 4. Summary of in vivo pharmacokinetic parameters of carebastine following the administration of EBT suspension, EBT plain film and EFT-5.

\begin{tabular}{cccc}
\hline \multirow{2}{*}{ Pharmacokinetic Parameters } & EBT Suspension & Plain Film & ETF-5 Transferosomal Film \\
\cline { 2 - 4 } & Group E & Group P & Group T \\
\hline $\mathrm{C}_{\max }(\mathrm{ng} / \mathrm{mL})$ & $78.4 \pm 2.31$ & $114.8 \pm 4.01$ & $152.3 \pm 2.18$ \\
$\mathrm{~T}_{\max }(\mathrm{h})$ & 4.6 & 4.1 & 7.8 \\
$\mathrm{t}_{1 / 2}(\mathrm{~h})$ & 19.12 & 18.64 & 22.6 \\
$\mathrm{AUC}_{0-72}(\mathrm{ng} / \mathrm{mL} / \mathrm{h})$ & $2116 \pm 32.51$ & $3697 \pm 12.04$ & $6249 \pm 21.7$ \\
$\mathrm{~K}_{\mathrm{e}}(1 / \mathrm{h})$ & 0.0372 & 0.0382 & 0.028 \\
\hline
\end{tabular}

\subsection{In Vivo Pharmacodynamics}

Table 5 shows the measurement of wheal at four different time points. ETF- 5 exhibited greater wheal suppression, as compared to placebo and pure drug (EBT). The suppression efficiency of the developed TOFs was much better than that of pure EBT after a single dose. ETF-5 suppressed the wheal and flare completely within $24 \mathrm{~h}$. Overall, antihistamine 
activity of ETF-5 was found superior with reference to all other tested products $(p<0.05)$. The disappearance of wheal and flare occurred with all treatments except placebo.

Table 5. Wheal area measurement for antihistaminic efficiency of pure EBT and developed TBF (ETF-5).

\begin{tabular}{ccccc}
\hline \multicolumn{5}{c}{ Wheal Area $\left(\mathbf{m m}^{\mathbf{2}}\right)$} \\
\hline Group & $\mathbf{0}$ h (Baseline) & $\mathbf{4} \mathbf{h}$ & $\mathbf{8} \mathbf{h}$ & $\mathbf{2 4} \mathbf{~ h}$ \\
\hline Placebo & $215.4 \pm 21.4$ & $221.2 \pm 18.6$ & $224.1 \pm 71.5$ & $193.4 \pm 13.2$ \\
Pure drug & $219.5 \pm 18.5$ & $114.5 \pm 12.1$ & $90.43 \pm 21.2$ & $55.3 \pm 3.14$ \\
ETF-5 & $211.8 \pm 11.8$ & $62.12 \pm 10.4$ & $12.42 \pm 1.4$ & $2.84 \pm 1.0$ \\
\hline
\end{tabular}

\section{Discussion}

A variety of studies were carried out to finalize the appropriate transfersomal formulation by varying the concentration of lipids and edge activators. The particle size, size distribution, entrapment efficiency and deformability were opted as selection criteria for the optimized transfersomal formulation [50]. A thin layer hydration method was found suitable for the development of transfersomes. Further, it was found from the results, that the nature of lipid, type of edge activator and manufacturing method played a critical role in the size reduction of transfersomes. The small size of transfersomes allows them to infiltrate membrane pores to increase bioavailability. The large multilamellar vesicles can be reduced to unilamellar vesicles (transfersomes) by probe sonication. The small size of transfersomes may be attributed to the amphiphilic nature of PC and EA as surfactants [51]. The PDI data expressed narrow particles distribution in the prepared formulation indicating a monodisperse population system (PDI < 0.1) [52]. The small size of transfersomes also increases the surface area of drug for diffusion. The negative zeta-potential could be due to the presence of PC in the formulations. In addition, the nonionic edge activators have nominal role in development of negative charge [53]. In addition, the concentration of phosphatidylcholine and EAs play a vital role in drug loading and entrapment efficiency [54]. As the concentration of PCs increases, the high EE is achieved [55]. The concentration of PC determines the entrapment efficiency of drug in transfersomes [56]. The EE of VS-1 and VT-1 was greater than rest of the formulations. Moreover, the deformability of transfersomes is attributed to EAs inculcated in vesicle bilayers [15]. The type of EA plays a dynamic role in the deformity and release properties of transfersomes [57]. Different edge activators (EA) (Polyoxyethylene sorbitan monooleate or sorbitan monolaurate) have different deformability properties. The results revealed that sorbitan monolaurate exhibited a better outcome in relative deformability of transfersomes than polysorbate- 80 . The HLB value of sorbitan monolaurate- 20 may be the reason for high lipophilicity, increasing deformability efficiency of lipid bilayers [58]. The maximum deformability of transfersomes was found with VS-3 [59].

TOFs exhibited good mechanical properties which could be due to the longer chain length of HPMC [60]. Clearly, the tensile strength, flexibility, elongation, thickness and weight of film are linked to film former polymer and plasticizer [32]. The physicochemical properties of film are directly associated with the release behavior of drug from films [61]. The DSC thermograms showed the sharp melting point of EBT to be around $82^{\circ} \mathrm{C}$, which was not seen in the thermograms of the optimized formulation (ETF-5), evidencing its conversion into amorphous form [62]. In addition, the flat peak confirms that the drug was well entrapped in the lipid bilayers. This was additionally confirmed by XRD data. Furthermore, no major shift in peaks was observed in the FTIR spectra, indicating stable entrapment of the drug in transfersomes. AFM morphological data identified smooth and uniform surface of the films containing transfersomes. The results obtained from the re-constitution of TOFs were similar to the original results; it means transfersomes were successfully developed upon re-dispersity of films. 
In vitro drug release from TOFs was sustained release which might be attributed to the bilayer of phosphatidylcholine and HPMC-K15M matrix. The drug release was retarded more in sorbitan monolaurate transfersomal formulations than in Tween ${ }^{\circledR}-80$ ones [63]. Further, the increase in the permeation flux is attributed to vesicle size and deformability property, which was largely influenced by sorbitan monolaurate. The permeation improvement can be due to small size transfersomes that can penetrate the pores of the membranes easily. In addition, the presence of EA increases the permeability by fluidizing lipid bilayers [64]. Thus, drug permeability through membranes may be attributed to size, lipophilicity and deformability of transfersomes [28].

After swallowing, films were partially degraded in the stomach and almost completely in the intestine. The transferosomes were released from the films and penetrated through the GIT membranes. A small quantity of EBT was released in the stomach, which is attributed to slow erosion and gel formation of HPMC-K15. Nevertheless, major drug release occurred in the intestine due to the dissolution of TOFs and high absorption of transfersomes. Transfersomes encapsulated EBT, thus drug release from transfersomes followed a sustain release pattern. The transfersomes in developed films were found very capable to cross the transmucosal tissues barriers, due to their ability to penetrate into deeper tissues along with the therapeutic agent to enhance bioavailability. The increased permeability of EBT confirmed the advantage of a combinational approach of transfersomes and oral film [65]. Transfersomes revealed improved and controlled release of EBT. The release of drug from plain film was governed by diffusion and erosion mechanisms, whereas TOFs followed a diffusion permeation mechanism. The concentration of EBT in plasma was not detected, thus the clinically relevant active metabolite carebastine was measured $[66,67]$. TOFs also have a significant impact on increasing the bioavailability of EBT, as depicted from pharmacokinetic findings of carebastine in in vivo studies. The increase in $T_{\max }$ could be related to the sustained drug release behavior of transfersomes. The increase in $\mathrm{T}_{\max }$ revealed that absorption had taken place for a longer time. The high value of $C_{\max }$ was possibly due to high absorption through transmucosal membranes. The area under curve (AUC) was increased significantly with developed ETF-5 oral film. The oral bioavailability of ETF-5 was increased 2.95 times, compared to pure EBT. Likewise, oral bioavailability of ETF-5 was improved 1.7 times, in comparison with plain film. The increase in the oral absorption rate might be linked to the deformability of transfersomes in films [68]. The small size of transfersomes increases the surface of drug molecules, subsequently maintaining the surface area in oral film. The released transfersomes enhanced the absorption through the mucosal membranes [69]. All these factors collectively led to increased bioavailability of EBT [70]. Previously, the transfersomal strategy consisted in delivering the therapeutic molecules through transdermal route [71,72]. Hence, in this novel work, the bioavailability of EBT was successfully enhanced through transfersomes-loaded oral films.

The antihistaminic effect of developed films loaded with transfersomes was strikingly superior to pure EBT [73]. The histamine-induced wheal was successfully suppressed by TOFs. Importantly, the pharmacodynamics showed superior efficiency of TOFs compared to plain film. This antihistaminic efficiency may be due to the presence of transfersomes in oral films. Overall, TOFs could be an effective delivery system to improve the bioavailability of EBT for the treatment of allergic rhinitis.

\section{Conclusions}

Transfersomes-loaded oral films (TOFs) were successfully developed as a carrier for transport of EBT. The developed transfersomes were ultra-deformable and flexible vesicles that penetrated significantly through mucosal membranes for enhancing the bioavailability of encapsulated EBT. The characteristic deformability property of transfersomes to pass through membrane pores was provided by edge activators in the prepared formulations. The permeability of transfersomes was attributed to sorbitan monolaurate which enriched the deformability of transfersomes. The higher bioavailability of EBT was achieved with TOFs than with plain film. The results obtained through entrapment-efficiency, deforma- 
bility, in vitro drug release, ex vivo permeation, relative oral bioavailability-support the novel carrier system (TOFs) as an improvement in the treatment of allergic rhinitis. Convincingly, the developed TOFs could be an effective carrier system for the delivery of poorly soluble EBT.

Author Contributions: Conceptualization, N.I. and M.I. (Muhammad Irfan); Data curation, A.F.Z. and S.-U.-D.K.; Formal analysis, M.S.I. and A.K.; Investigation, H.K.S. and M.I. (Muzzamil Ikram); Methodology, N.I. and A.M.A.; Resources, I.U.K. and M.A.S.A.; Software, A.R. and M.A.Q.; Validation, S.I.; Visualization, M.I. (Muhammad Irfan); Writing—original draft, N.I; Writing—review \& editing, M.I. (Muhammad Irfan). All authors have read and agreed to the published version of the manuscript.

Funding: This research received no external funding.

Institutional Review Board Statement: The approval for animal experiments was given by the Institutional Review Committee, Government College University Faisalabad (Ref No. GCUF/ERC/2068, Study No. 19668, IRB No. 668, 5 September 2019).

Informed Consent Statement: Not applicable, as humans were not involved in this study.

Data Availability Statement: The data presented in this study are available on request from the corresponding author. The data are not publicly available as it was originally produced through research.

Acknowledgments: Authors would like to recognize the generous support of Apsis Pharmaceutical, Gujranwala, Pakistan, for offering their laboratories for the performance of this research work.

Conflicts of Interest: The authors declare no conflict of interest.

\section{References}

1. Antonijoan, R.; García-Gea, C.; Puntes, M.; Pérez, J.; Esbrí, R.; Serra, C.; Fortea, J.; Barbanoj, M.J. Comparison of inhibition of cutaneous histamine reaction of ebastine fast-dissolving tablet $(20 \mathrm{mg}$ ) versus desloratadine capsule (5 mg): A randomized, double-blind, double-dummy, placebo-controlled, three-period crossover study in healthy, nonatopic adults. Clin. Ther. 2007, 29, 814-822. [CrossRef] [PubMed]

2. Dierick, B.J.; van der Molen, T.; Flokstra-de Blok, B.M.; Muraro, A.; Postma, M.J.; Kocks, J.W.; van Boven, J.F. Burden and socioeconomics of asthma, allergic rhinitis, atopic dermatitis and food allergy. Expert Rev. Pharm. Outcomes Res. 2020, 20, 437-453. [CrossRef] [PubMed]

3. Sastre, J. Ebastine in the treatment of allergic rhinitis and urticaria: 30 years of clinical studies and real-world experience. J. Investig. Allergol. Clin. Immunol. 2020, 30, 156-168. [CrossRef]

4. Gispert, J.; Antonijoan, R.; Barbanoj, M.; Gich, I.; Garcia, E.; Esbrí, R.; Luria, X. Efficacy of ebastine, cetirizine, and loratadine in histamine cutaneous challenges. Ann. Allergy Asthma Immunol. 2002, 89, 259-264. [CrossRef]

5. Islam, N.; Zahoor, A.F.; Syed, H.K.; Iqbal, M.S.; Khan, I.U.; Abbas, G.; Mushtaq, M.; Rehman, M.U.; Rasul, A.; Ikram, M. Improvement of solubility and dissolution of ebastine by fabricating phosphatidylcholine/bile salt bilosomes. Pak. J. Pharm. Sci 2020, 33, 2301-2306.

6. Wouters, M.M.; Balemans, D.; Van Wanrooy, S.; Dooley, J.; Cibert-Goton, V.; Alpizar, Y.A.; Valdez-Morales, E.E.; Nasser, Y.; Van Veldhoven, P.P.; Vanbrabant, W. Histamine receptor H1-mediated sensitization of TRPV1 mediates visceral hypersensitivity and symptoms in patients with irritable bowel syndrome. Gastroenterology 2016, 150, 875-887.e9. [CrossRef]

7. Rico, S.; Antonijoan, R.; Barbanoj, M. Ebastine in the light of CONGA recommendations for the development of third-generation antihistamines. J. Asthma Allergy 2009, 2, 73.

8. Mahajan, V.R.; Basarkar, G.D. Formulation, characterization, and in vitro-in vivo evaluation of self microemulsifying drug delivery system of Ebastine by spray drying technology using solid carriers. Thai J. Pharm. Sci. 2019, 43, 146-160.

9. Kamisetti, R.R.; Gupta, V. Solubility enhancement of ebastine by self-nanoemulsifying delivery strategy: Formulation, optimization and characterization. Int. J. Pharmcutical Sci. Nanotechnol. 2017, 10, 3779-3787.

10. Mehetre, J.; Vimal, K.; Mehta, T.; Gohel, M.; Surti, N. Rationalized Approach for Formulation and Optimization of Ebastine Microemulsion Using Design Expert for Solubility Enhancement. J. Drug Deliv. Ther. 2019, 9, 386-397.

11. Harmalkar, D.; Godinho, S.; Bhide, P.J.; Kumar, L.; Shirodkar, R.K. New Formulation Technique for Solubility and Dissolution Rate Enhancement of Poorly Soluble Drugs. Pharm. Chem. J. 2019, 53, 720-729. [CrossRef]

12. Banala, N.; Peddapalli, H.; Dudhipala, N.; Chinnala, K.M. Transmucosal Delivery of Duloxetine Hydrochloride for Prolonged Release: Preparation, in vitro, ex vivo Characteri-zation and in vitro-ex vivo Correlation. Int. J. Pharm. Sci. Nanotechnol. 2018, 11, 4249-4258. [CrossRef]

13. Singh, R.P.; Gangadharappa, H.; Mruthunjaya, K. Phospholipids: Unique carriers for drug delivery systems. J. Drug Deliv. Sci. Technol. 2017, 39, 166-179. [CrossRef] 
14. Perez, A.P.; Altube, M.J.; Schilrreff, P.; Apezteguia, G.; Celes, F.S.; Zacchino, S.; de Oliveira, C.I.; Romero, E.L.; Morilla, M.J. Topical amphotericin B in ultradeformable liposomes: Formulation, skin penetration study, antifungal and antileishmanial activity in vitro. Colloids Surf. B Biointerfaces 2016, 139, 190-198. [CrossRef]

15. El Zaafarany, G.M.; Awad, G.A.; Holayel, S.M.; Mortada, N.D. Role of edge activators and surface charge in developing ultradeformable vesicles with enhanced skin delivery. Int. J. Pharm. 2010, 397, 164-172. [CrossRef] [PubMed]

16. Cristiano, M.C.; Cilurzo, F.; Carafa, M.; Paolino, D. Innovative vesicles for dermal and transdermal drug delivery. In Lipid Nanocarriers for Drug Targeting; Elsevier: Amsterdam, The Netherlands, 2018; pp. 175-197.

17. Wang, J.; Wei, Y.; Fei, Y.-R.; Fang, L.; Zheng, H.-S.; Mu, C.-F.; Li, F.-Z.; Zhang, Y.-S. Preparation of mixed monoterpenes edge activated PEGylated transfersomes to improve the in vivo transdermal delivery efficiency of sinomenine hydrochloride. Int. $J$. Pharm. 2017, 533, 266-274. [CrossRef] [PubMed]

18. Rai, S.; Pandey, V.; Rai, G. Transfersomes as versatile and flexible nano-vesicular carriers in skin cancer therapy: The state of the art. Nano Rev. Exp. 2017, 8, 1325708. [CrossRef] [PubMed]

19. Khan, I.; Apostolou, M.; Bnyan, R.; Houacine, C.; Elhissi, A.; Yousaf, S.S. Paclitaxel-loaded micro or nano transfersome formulation into novel tablets for pulmonary drug delivery via nebulization. Int. J. Pharm. 2020, 575, 118919. [CrossRef] [PubMed]

20. Kumria, R.; Nair, A.B.; Goomber, G.; Gupta, S. Buccal films of prednisolone with enhanced bioavailability. Drug Deliv. 2016, 23, 471-478. [CrossRef]

21. Montenegro-Nicolini, M.; Morales, J.O. Overview and future potential of buccal mucoadhesive films as drug delivery systems for biologics. AAPS Pharmscitech 2017, 18, 3-14. [CrossRef] [PubMed]

22. Ahmed, T.A.; Bawazir, A.O.; Alharbi, W.S.; Safo, M.K. Enhancement of Simvastatin ex vivo Permeation from Mucoadhesive Buccal Films Loaded with Dual Drug Release Carriers. Int. J. Nanomed. 2020, 15, 4001-4020. [CrossRef]

23. Zaman, M.; Hanif, M.; Shaheryar, Z.A. Development of Tizanidine HCl-Meloxicam loaded mucoadhesive buccal films: In-vitro and in-vivo evaluation. PLoS ONE 2018, 13, e0194410. [CrossRef]

24. Kraisit, P.; Limmatvapirat, S.; Luangtana-Anan, M.; Sriamornsak, P. Buccal administration of mucoadhesive blend films saturated with propranolol loaded nanoparticles. Asian J. Pharm. Sci. 2018, 13, 34-43. [CrossRef] [PubMed]

25. Islam, N.; Irfan, M.; Abbas, N.; Syed, H.K.; Iqbal, M.S.; ullah Khan, I.; Rasul, A.; Inam, S.; Hussain, A.; Arshad, M.S. Enhancement of solubility and dissolution rate of ebastine fast-disintegrating tablets by solid dispersion method. Trop. J. Pharm. Res. 2020, 19, 1797-1805. [CrossRef]

26. Haraguchi, T.; Yoshida, M.; Uchida, T. Evaluation of ebastine-loaded orally disintegrating tablets using new apparatus of detecting disintegration time and e-tongue system. J. Drug Deliv. Sci. Technol. 2014, 24, 684-688. [CrossRef]

27. Roger, A.; Fortea, J.; Mora, S.; Artés, M. Ebastine fast-dissolving tablets versus regular tablets: Acceptability and preference in patients with allergic rhinitis. Expert Rev. Clin. Pharmacol. 2008, 1, 381-389. [CrossRef]

28. Jadhav, S.B.; Koshti, A.R.; Bari, M.; Barhate, S. Formulation optimization and Evaluation of Transdermal patch of losartan potassium containing DMSO as permeation enhancer. Asian J. Pharm. Technol. 2019, 9, 220-227. [CrossRef]

29. Elkomy, M.H.; El Menshawe, S.F.; Abou-Taleb, H.A.; Elkarmalawy, M.H. Loratadine bioavailability via buccal transferosomal gel: Formulation, statistical optimization, in vitro/in vivo characterization, and pharmacokinetics in human volunteers. Drug Deliv. 2017, 24, 781-791. [CrossRef]

30. Speer, I.; Preis, M.; Breitkreutz, J. Dissolution testing of oral film preparations: Experimental comparison of compendial and non-compendial methods. Int. J. Pharm. 2019, 561, 124-134. [CrossRef] [PubMed]

31. Omar, M.M.; Hasan, O.A.; El Sisi, A.M. Preparation and optimization of lidocaine transferosomal gel containing permeation enhancers: A promising approach for enhancement of skin permeation. Int. J. Nanomed. 2019, 14, 1551. [CrossRef]

32. Otoni, C.G.; Lorevice, M.V.; de Moura, M.R.; Mattoso, L.H. On the effects of hydroxyl substitution degree and molecular weight on mechanical and water barrier properties of hydroxypropyl methylcellulose films. Carbohydr. Polym. 2018, 185, 105-111. [CrossRef]

33. Leonyza, A.; Surini, S. Optimization of sodium deoxycholate-based transfersomes for percutaneous delivery of peptides and proteins. Int. J. Appl. Pharm. 2019, 11, 329-332. [CrossRef]

34. Shuwaili, A.H.A.; Rasool, B.K.A.; Abdulrasool, A.A. Optimization of elastic transfersomes formulations for transdermal delivery of pentoxifylline. Eur. J. Pharm. Biopharm. 2016, 102, 101-114. [CrossRef]

35. Wang, L.-L.; He, D.-D.; Wang, S.-X.; Dai, Y.-H.; Ju, J.-M.; Zhao, C.-L. Preparation and evaluation of curcumin-loaded self-assembled micelles. Drug Dev. Ind. Pharm. 2018, 44, 563-569. [CrossRef]

36. Prateepchanachai, S.; Thakhiew, W.; Devahastin, S.; Soponronnarit, S. Mechanical properties improvement of chitosan films via the use of plasticizer, charge modifying agent and film solution homogenization. Carbohydr. Polym. 2017, 174, 253-261. [CrossRef]

37. Speer, I.; Steiner, D.; Thabet, Y.; Breitkreutz, J.; Kwade, A. Comparative study on disintegration methods for oral film preparations. Eur. J. Pharm. Biopharm. 2018, 132, 50-61. [CrossRef] [PubMed]

38. Hanif, M.; Zaman, M. Thiolation of arabinoxylan and its application in the fabrication of controlled release mucoadhesive oral films. DARU J. Pharm. Sci. 2017, 25, 6. [CrossRef] [PubMed]

39. Takeuchi, Y.; Ikeda, N.; Tahara, K.; Takeuchi, H. Mechanical characteristics of orally disintegrating films: Comparison of folding endurance and tensile properties. Int. J. Pharm. 2020, 589, 119876. [CrossRef]

40. Talekar, S.D.; Haware, R.V.; Dave, R.H. Evaluation of self-nanoemulsifying drug delivery systems using multivariate methods to optimize permeability of captopril oral films. Eur. J. Pharm. Sci. 2019, 130, 215-224. [CrossRef] [PubMed] 
41. Mazumder, S.; Pavurala, N.; Manda, P.; Xu, X.; Cruz, C.N.; Krishnaiah, Y.S. Quality by Design approach for studying the impact of formulation and process variables on product quality of oral disintegrating films. Int. J. Pharm. 2017, 527, 151-160. [CrossRef] [PubMed]

42. Rathore, R.; Gupta, A.K.; Parashar, A.K. Formulation and Evaluation of fast dissolving films of Granisetron Hydrochloride. J. Drug Deliv. Ther. 2019, 9, 36-38.

43. Islam, N.; Irfan, M.; Khan, S.-U.-D.; Syed, H.K.; Iqbal, M.S.; Khan, I.U.; Mahdy, A.; Raafat, M.; Hossain, M.A.; Inam, S. Poloxamer188 and d- $\alpha$-Tocopheryl Polyethylene Glycol Succinate (TPGS-1000) Mixed Micelles Integrated Orodispersible Sublingual Films to Improve Oral Bioavailability of Ebastine; In Vitro and In Vivo Characterization. Pharmaceutics 2021, 13, 54. [CrossRef]

44. Shamma, R.N.; Elsayed, I. Transfersomal lyophilized gel of buspirone HCl: Formulation, evaluation and statistical optimization J. Liposome Res. 2013, 23, 244-254. [CrossRef]

45. Balguri, S.P.; Adelli, G.R.; Majumdar, S. Topical ophthalmic lipid nanoparticle formulations (SLN, NLC) of indomethacin for delivery to the posterior segment ocular tissues. Eur. J. Pharm. Biopharm. 2016, 109, 224-235. [CrossRef] [PubMed]

46. Qin, Z.-y.; Jia, X.-W.; Liu, Q.; Kong, B.-h.; Wang, H. Fast dissolving oral films for drug delivery prepared from chitosan/pullulan electrospinning nanofibers. Int. J. Biol. Macromol. 2019, 137, 224-231. [CrossRef] [PubMed]

47. Pitta, S.K.; Dudhipala, N.; Narala, A.; Veerabrahma, K. Development of zolmitriptan transfersomes by Box-Behnken design for nasal delivery: In vitro and in vivo evaluation. Drug Dev. Ind. Pharm. 2018, 44, 484-492. [CrossRef] [PubMed]

48. Castro, P.M.; Baptista, P.; Zuccheri, G.; Madureira, A.R.; Sarmento, B.; Pintado, M.E. Film-nanoparticle composite for enhanced oral delivery of alpha-casozepine. Colloids Surf. B Biointerfaces 2019, 181, 149-157. [CrossRef] [PubMed]

49. Al-Mahallawi, A.M.; Khowessah, O.M.; Shoukri, R.A. Enhanced non invasive trans-tympanic delivery of ciprofloxacin through encapsulation into nano-spanlastic vesicles: Fabrication, in-vitro characterization, and comparative ex-vivo permeation studies. Int. J. Pharm. 2017, 522, 157-164. [CrossRef]

50. Rahmi, A.D.; Pangesti, D.M. Comparison of the Characteristics of Transfersomes and Protransfersomes Containing Azelaic Acid. J. Young Pharm. 2018, 10, S11.

51. Abdel-Hafez, S.M.; Hathout, R.M.; Sammour, O.A. Curcumin-loaded ultradeformable nanovesicles as a potential delivery system for breast cancer therapy. Colloids Surf. B Biointerfaces 2018, 167, 63-72. [CrossRef]

52. Ingallina, C.; Rinaldi, F.; Bogni, A.; Ponti, J.; Passeri, D.; Reggente, M.; Rossi, M.; Kinsner-Ovaskainen, A.; Mehn, D.; Rossi, F. Niosomal approach to brain delivery: Development, characterization and in vitro toxicological studies. Int. J. Pharm. 2016, 511, 969-982. [CrossRef]

53. Garg, V.; Singh, H.; Bimbrawh, S.; Kumar Singh, S.; Gulati, M.; Vaidya, Y.; Kaur, P. Ethosomes and transfersomes: Principles, perspectives and practices. Curr. Drug Deliv. 2017, 14, 613-633. [CrossRef] [PubMed]

54. Farzaneh, H.; Nik, M.E.; Mashreghi, M.; Saberi, Z.; Jaafari, M.R.; Teymouri, M. A study on the role of cholesterol and phosphatidylcholine in various features of liposomal doxorubicin: From liposomal preparation to therapy. Int. J. Pharm. 2018, 551, 300-308. [CrossRef]

55. Shreya, A.; Managuli, R.S.; Menon, J.; Kondapalli, L.; Hegde, A.R.; Avadhani, K.; Shetty, P.K.; Amirthalingam, M.; Kalthur, G.; Mutalik, S. Nano-transfersomal formulations for transdermal delivery of asenapine maleate: In vitro and in vivo performance evaluations. J. Liposome Res. 2016, 26, 221-232. [CrossRef] [PubMed]

56. Dudhipala, N.; Phasha Mohammed, R.; Adel Ali Youssef, A.; Banala, N. Effect of lipid and edge activator concentration on development of aceclofenac-loaded transfersomes gel for transdermal application: In vitro and ex vivo skin permeation. Drug Dev. Ind. Pharm. 2020, 46, 1334-1344. [CrossRef]

57. Fernández-García, R.; Lalatsa, A.; Statts, L.; Bolás-Fernández, F.; Ballesteros, M.P.; Serrano, D.R. Transferosomes as nanocarriers for drugs across the skin: Quality by design from lab to industrial scale. Int. J. Pharm. 2020, 573, 118817. [CrossRef]

58. Moawad, F.A.; Ali, A.A.; Salem, H.F. Nanotransfersomes-loaded thermosensitive in situ gel as a rectal delivery system of tizanidine $\mathrm{HCl}$ : Preparation, in vitro and in vivo performance. Drug Deliv. 2017, 24, 252-260. [CrossRef]

59. Zeb, A.; Qureshi, O.S.; Kim, H.-S.; Cha, J.-H.; Kim, H.-S.; Kim, J.-K. Improved skin permeation of methotrexate via nanosized ultradeformable liposomes. Int. J. Nanomed. 2016, 11, 3813.

60. Bodini, R.B.; das Graças Lapa Guimarães, J.; Monaco-Lourenço, C.A.; de Carvalho, R.A. Effect of starch and hydroxypropyl methylcellulose polymers on the properties of orally disintegrating films. J. Drug Deliv. Sci. Technol. 2019, 51, 403-410. [CrossRef]

61. Yildiz Pekoz, A.; Sedef Erdal, M.; Okyar, A.; Ocak, M.; Tekeli, F.; Kaptan, E.; Sagirli, O.; Araman, A. Preparation and in-vivo evaluation of dimenhydrinate buccal mucoadhesive films with enhanced bioavailability. Drug Dev. Ind. Pharm. 2016, 42, 916-925. [CrossRef] [PubMed]

62. Gajera, B.Y.; Shah, D.A.; Dave, R.H. Development of an amorphous nanosuspension by sonoprecipitation-formulation and process optimization using design of experiment methodology. Int. J. Pharm. 2019, 559, 348-359. [CrossRef]

63. Morsi, N.M.; Aboelwafa, A.A.; Dawoud, M.H. Enhancement of the bioavailability of an antihypertensive drug by transdermal protransfersomal system: Formulation and in vivo study. J. Liposome Res. 2018, 28, 137-148. [CrossRef]

64. Sundralingam, U.; Muniyandy, S.; Radhakrishnan, A.K.; Palanisamy, U.D. Ratite oils for local transdermal therapy of 4-OH Tamoxifen: Development, Characterization and Ex-vivo Evaluation. J. Liposome Res. 2020, 31, 217-229. [CrossRef] [PubMed]

65. Pandit, A.P.; Omase, S.B.; Mute, V.M. A chitosan film containing quercetin-loaded transfersomes for treatment of secondary osteoporosis. Drug Deliv. Transl. Res. 2020, 10, 1495-1506. [CrossRef] 
66. Tamai, I.; Kido, Y.; Yamashita, J.; Sai, Y.; Tsuji, A. Blood-brain barrier transport of H1-antagonist ebastine and its metabolite carebastine. J. Drug Target. 2000, 8, 383-393. [CrossRef] [PubMed]

67. Liu, K.-H.; Kim, M.-G.; Lee, D.-J.; Yoon, Y.-J.; Kim, M.-J.; Shon, J.-H.; Choi, C.S.; Choi, Y.K.; Desta, Z.; Shin, J.-G. Characterization of ebastine, hydroxyebastine, and carebastine metabolism by human liver microsomes and expressed cytochrome P450 enzymes: Major roles for CYP2J2 and CYP3A. Drug Metab. Dispos. 2006, 34, 1793-1797. [CrossRef] [PubMed]

68. Senna, T.D.; Mata dos Santos, H.A.; Kibwila, D.M.; Leitao, A.C.; Dos Santos Pyrrho, A.; de Padula, M.; Rosas, E.C.; Padua, T.A.; Lara, M.G.; Riemma Pierre, M.B. In vitro and in vivo evaluation of DMSO and azone as penetration enhancers for cutaneous application of celecoxib. Curr. Drug Deliv. 2017, 14, 992-1004. [CrossRef]

69. Yang, T.-Z.; Wang, X.-T.; Yan, X.-Y.; Zhang, Q. Phospholipid deformable vesicles for buccal delivery of insulin. Chem. Pharm. Bull. 2002, 50, 749-753. [CrossRef]

70. Badr-Eldin, S.M.; Ahmed, O.A. Optimized nano-transfersomal films for enhanced sildenafil citrate transdermal delivery: Ex vivo and in vivo evaluation. Drug Des. Devel. Ther. 2016, 10, 1323. [CrossRef]

71. Ahad, A.; Al-Saleh, A.A.; Al-Mohizea, A.M.; Al-Jenoobi, F.I.; Raish, M.; Yassin, A.E.B.; Alam, M.A. Formulation and characterization of Phospholipon $90 \mathrm{G}$ and tween 80 based transfersomes for transdermal delivery of eprosartan mesylate. Pharm. Dev. Technol. 2018, 23, 787-793. [CrossRef]

72. Opatha, S.A.T.; Titapiwatanakun, V.; Chutoprapat, R. Transfersomes: A promising nanoencapsulation technique for transdermal drug delivery. Pharmaceutics 2020, 12, 855. [CrossRef] [PubMed]

73. Antonijoan, R.; Coimbra, J.; García-Gea, C.; Puntes, M.; Gich, I.; Campo, C.; Valiente, R.; Labeaga, L. Comparative efficacy of bilastine, desloratadine and rupatadine in the suppression of wheal and flare response induced by intradermal histamine in healthy volunteers. Curr. Med. Res. Opin. 2017, 33, 129-136. [CrossRef] [PubMed] 